\title{
The Formin DAAM Functions as Molecular Effector of the Planar Cell Polarity Pathway during Axonal Development in Drosophila
}

\author{
Rita Gombos, ${ }^{1,2}$ Ede Migh, ${ }^{1}{ }^{\mathbb{C}}$ Otilia Antal, ${ }^{1}$ Anindita Mukherjee, ${ }^{3}$ Andreas Jenny, ${ }^{3}$ and József Mihály ${ }^{1,2}$ \\ ${ }^{1}$ Institute of Genetics, Biological Research Centre HAS, H-6726, Szeged, Hungary, ${ }^{2}$ Hungarian Academy of Sciences, Office for Subsidized Research Units, \\ Budapest, H-1051, Hungary, and 3 Department of Developmental and Molecular Biology, Albert Einstein College of Medicine, Bronx, New York 10461
}

Recent studies established that the planar cell polarity (PCP) pathway is critical for various aspects of nervous system development and function, including axonal guidance. Although it seems clear that PCP signaling regulates actin dynamics, the mechanisms through which this occurs remain elusive. Here, we establish a functional link between the PCP system and one specific actin regulator, the formin DAAM, which has previously been shown to be required for embryonic axonal morphogenesis and filopodia formation in the growth cone. We show that $D D A A M$ also plays a pivotal role during axonal growth and guidance in the adult Drosophila mushroom body, a brain center for learning and memory. By using a combination of genetic and biochemical assays, we demonstrate that Wnt5 and the PCP signaling proteins Frizzled, Strabismus, and Dishevelled act in concert with the small GTPase Rac1 to activate the actin assembly functions of dDAAM essential for correct targeting of mushroom body axons. Collectively, these data suggest that dDAAM is used as a major molecular effector of the PCP guidance pathway. By uncovering a signaling system from the Wnt5 guidance cue to an actin assembly factor, we propose that the Wnt5/PCP navigation system is linked by dDAAM to the regulation of the growth cone actin cytoskeleton, and thereby growth cone behavior, in a direct way.

Key words: axon growth; dDAAM; Drosophila; formin; mushroom body; PCP

\section{Introduction}

To form functional neuronal circuits, neurons send out axons and dendrites to defined target sites where they make synaptic connections. Proper navigation of axons is governed by attractive and repulsive guidance cues through the modulation of cytoskeletal dynamics in the axonal growth cones (Chilton, 2006; Lowery and Van Vactor, 2009). In addition to the classical Ephrin, Semaphorin, Netrin, and Slit guidance systems (Huber et al., 2003), morphogens, such as Wnts, are also key regulators of growth cone behavior (Yam and Charron, 2013). Wnt proteins signal through canonical and noncanonical pathways, of which the noncanonical Wnt/planar cell polarity (PCP) pathway guides axons in various types of neurons (Yam and Charron, 2013). However, the

\footnotetext{
Received Sept. 5, 2014; revised May 14, 2015; accepted June 4, 2015.

Author contributions: R.G., E.M., A.J., and J.M. designed research; R.G., E.M., O.A., A.M., and A.J. performed research; R.G., E.M., A.J., and J.M. analyzed data; R.G., A.J., and J.M. wrote the paper.

This work was supported by Hungarian Brain Research Program KTIA_NAP_13-2014-0007, Hungarian Scientific Research Foundation OTKA Grants K82039 and 109330 to J.M., and National Institutes of Health Grant R01GM088202 to A.J., R.G was supported by the European Union and the State of Hungary, cofinanced by the European Social Fund in the framework of TÁMOP-4.2.4.A/ 2-11/1-2012-0001 National Excellence Program. We thank Andor Udvardy, Tadashi Uemura, Lee Fradkin, and Francois Schweisguth; the Developmental Studies Hybridoma Bank; the Bloomington and Kyoto Stock Centers; the VDRC for fly stocks and reagents; Henrik Gyurkovics, Péter Vilmos, Ferenc Jankovics, and in particular Andreas Prokop, for critical reading and helpful comments on the manuscript; and Anna Rehák, Anikó Berente, Szilvia Bozsó, and Velkeyné lldikó Krausz for technical assistance.

The authors declare no competing financial interests.

Correspondence should be addressed to Dr. József Mihály, Institute of Genetics, Biological Research Centre, Hungarian Academy of Sciences, H-6726 Szeged, Temesvári krt 62, Hungary. E-mail: mihaly.jozsef@brc.mta.hu.

DOI:10.1523/JNEUROSCI.3708-14.2015

Copyright $\odot 2015$ the authors $\quad 0270-6474 / 15 / 3510154-14 \$ 15.00 / 0$
}

molecular mechanisms of the PCP system during neuronal development are poorly understood.

PCP is an important aspect of differentiation when cells acquire a coordinated polarization within the plane of a tissue. PCP is regulated by an evolutionary highly conserved signaling pathway initially discovered in Drosophila (Adler, 2002; Goodrich and Strutt, 2011). The central elements of this regulatory system are the core PCP genes, including frizzled $(f z)$, dishevelled (dsh), Van Gogh (Vang) (also known as strabismus, stbm), prickle ( $p$ k), and flamingo ( fmi) (also known as starry night, stan) (Adler, 2002; Maung and Jenny, 2011). In addition to planar polarization, the PCP factors are also involved in the regulation of several aspects of CNS development, including axonal guidance, both in Drosophila and vertebrates (Lee et al., 2003; Senti et al., 2003; Goodrich, 2008; Wada and Okamoto, 2009; Tissir and Goffinet, 2010), but the molecular effectors of the core PCP module during neuronal differentiation remain elusive.

Vertebrate studies revealed that a formin type of actin assembly factor (Wallar and Alberts, 2003; Chesarone et al., 2010), DAAM (Dishevelled Associated Activator of Morphogenesis), is a component of the PCP pathway during gastrulation (Habas et al., 2001). By contrast, it was shown that the Drosophila ortholog is not required for tissue polarization (Matusek et al., 2006). Interestingly, however, dDAAM plays a crucial role during axonal growth in embryonic neurons (Matusek et al., 2008; Gonçalves-Pimentel et al., 2011; Prokop et al., 2011), which made it a good candidate to link the PCP system to cytoskeleton regulation in the CNS. 
Here we show that DDAAM is highly enriched in the neuropile region of the brain, including the newly forming axons of the mushroom bodies (MBs). We report that $D D A A M$ functions together with the core PCP factors and Wnt5 to promote correct projection of the $\mathrm{MB}$ axons. Whereas previous studies established that Wnt5 and the PCP pathway act concertedly during axonal development (Shimizu et al., 2011; Ng, 2012), our results suggest that the PCP navigation system is linked to direct changes in the growth cone actin cytoskeleton through Racl and the formin dDAAM. In addition, we propose that, in contrast to the tissue polarity function of DAAM, the axonal guidance function of the $\mathrm{PCP} / \mathrm{DAAM}$ regulatory module is likely to be conserved during evolution.

\section{Materials and Methods}

Fly strains and genetics. The following mutant strains were used: $d s h^{1} ; f z^{20}$; $f z^{23} ; f z^{30} ; p k^{30} ; f m i^{f r z 3} ; V a n g^{s t b m-6} ; W n t 5^{400}$ (a kind gift from L.G. Fradkin); $\operatorname{Racl}^{J 11} ; R h o A^{72 F} ; C d c 42^{3}$ and $d D A A M^{E x 1}$, which are described in details in Flybase. As transgenic lines, we used act-Gal4; elav-Gal4; OK107-Gal4; NP6024-Gal4 (Tanaka et al., 2008); UAS-mCD8::GFP; UAS-FLDAAM; UAS-C-DAAM; UAS-DADmDAAM; UAS-Wnt5 (a kind gift from L.G. Fradkin) and UAS-Vang-GFP (a kind gift from Francois Schweisguth), which are described in the references indicated or in Flybase. The UAS-FLDAAM-I732A::Flag and the UAS-FLDAAM GBD2 lines were created with standard in vitro mutagenesis techniques. The $d D A A M^{E x 1}<d s h^{1} ; d D A A M^{E x 1}<W n t 5^{400}$ and the $d D A A M^{E x l}<C d c 42^{3}$ recombinant chromosomes were created by standard recombination methods. The $d D A A M^{E x 4}$ excision allele was generated by remobilization of the $P($ GawB $) N P 6041$ P-element insertion. A total of 200 dysgenic males were crossed individually to $y, w, l(1) / y, w, F M 6$ females to recover excisions and establish stocks subsequently. Sequence analysis revealed that $d D A A M^{E x 4}$ carries a 1293 bps deletion affecting the first exon and intron of the predicted dDAAM-PB isoform. Unless indicated, flies were raised at $25^{\circ} \mathrm{C}$ under standard conditions. Fisher's exact test was used as statistical method to determine the significance of the dominant genetic interaction assays.

To generate single-cell and neuroblast clones in the $\mathrm{MB}$, we used the mosaic analysis with a repressible cell marker (MARCM) technique (Lee and Luo, 1999). For $d D A A M$ mutant single-cell clones $d D A A M^{E \times 68}$ FRT19A/ tubG80 FRT19A, hsFlp; UAS-mCD8::GFP/+; elavG4/+ or $d D A A M^{E x 4} / Y$; hsFLP/UAS-mCD8::GFP; FRT80B, tubP-Gal80/FRT80B; OK107-Gal4/+, for wild-type control clones elav-Gal4, UAS-mCD8::GFP, $h s F L P /+$; FRT80B, tubP-Gal80/FRT80B pupae were heat-shocked at $37^{\circ} \mathrm{C}$ for $30 \mathrm{~min}$ at $50 \mathrm{~h}$ after puparium formation. For neuroblast clones, first instar larvae of the same genotypes were heat-shocked at $37^{\circ} \mathrm{C}$ for $30 \mathrm{~min}$. The morphology of the MB clones was analyzed in flies 3-7 d old.

Immunohistochemistry. Adult, larval, and pupal brains were dissected in cold PBS, fixed in 4\% PFA (diluted in PBS) at room temperature for 20 min; primary antibodies were applied overnight at $4^{\circ} \mathrm{C}$. After the secondary antibodies and standard washing steps, samples were mounted in PBS:glycerin (1:4). Confocal images were captured on an Olympus FV1000 LSM microscope. Images were edited with Adobe Photoshop 7.0CE and Olympus FW10-ASW. We used rabbit $\alpha$-dDAAM (1:2000) (specificity of which is verified with the $d D A A M^{\text {Ex68-null }}$ mutant, shown in Matusek et al., 2006) and mouse $\alpha$-FasII (1:50) (DSHB, 1D4) as primary antibodies, and the corresponding Alexa- 488 or Alexa- 546 coupled secondary antibodies (Invitrogen).

Western blot. As lysis buffer, we used the solution of $0.1 \%$ SDS, $0.2 \%$ NaDoc; $0.05 \%$ NP40, $150 \mathrm{~mm} \mathrm{NaCl}$, and $50 \mathrm{~mm}$ Tris-HCl. SDS-PAGE was done according to standard protocols. After blotting, PVDF membranes (Millipore) were blocked in TBST $+5 \%$ dry milk powder for $1 \mathrm{~h}$ at room temperature. Primary antibodies used were rabbit $\alpha$-dDAAM (1: 1000) (Matusek et al., 2006), and rabbit $\alpha$-glycogen phosphorylase (1: 20,000 ) (kindly provided by A. Udvardy). Secondary antibodies were $\alpha$-rabbit-HRPO $(1: 10,000)$ (Sigma) and $\alpha$-mouse-HRPO (1:5000) (DAKO). For chemiluminescent detection we used a Millipore Immobilon kit.
Plasmids and transfections. For generation of GST fusion proteins, a DNA fragment encoding N-DAAM was subcloned into pGEX-6p-1, whereas the C-DAAM encoding fragment was subcloned into pGEX-2T. For S2 cell transfections, the following constructs were used: pAc5.1-FzRFP, pAc5.1-Fz-Flag, pAc5.1-Dsh-myc, pAc5.1-Dsh-GFP, pAc5.1Vang-Flag, pAWF-dDAAM, and pAWH-dDAAM.

A total of $2 \times 10^{5} \mathrm{~S} 2$ cells per well were plated onto poly-lysine-coated Labtech chamber slides and transfected on the following day with a total of $300 \mathrm{ng}$ DNA using Effectene (QIAGEN) according to the manufacturer's instructions. After $48 \mathrm{~h}$, cells were fixed with $4 \%$ PFA for $10 \mathrm{~min}$ at room temperature and stained as described previously (Matusek et al., 2008). The RNAi knockdown experiment was performed according to published protocols (Clemens et al., 2000). Sequence of the Wnt5 dsRNA was provided by L.G. Fradkin (Petrova et al., 2013). As negative control, we used a dsRNA targeting bel (a gene with no known function in PCP) (primers: $5^{\prime}$-GGATCCTAATACGACTCACTATAGGGCACCAGACCCAAC

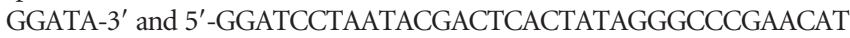
CACATCGTT- $3^{\prime}$ ). Primary antibodies used were mouse $\alpha$-Flag M2 (Sigma), mouse $\alpha$-Myc 9E11 (1:500) (Santa Cruz Biotechnology), rat $\alpha$-HA (1:250) (Roche), rabbit $\alpha$-GFP (1:400) (Invitrogen), and rabbit $\alpha$-WNT5 (1:2500) (kindly provided by L.G. Fradkin). Corresponding Alexa-488, -568, and -647 coupled secondary antibodies (Invitrogen) were used at 1:600.

GST pulldown. GST-C-DAAM, GST-N-DAAM, and GST proteins were expressed in BL21 codon ${ }^{+}$bacterial cells at $18^{\circ} \mathrm{C}$. Bacterial cells were harvested and sonicated 3 times with $20 \mathrm{~s}$ bursts in PBS at $4^{\circ} \mathrm{C}$. After centrifugation the supernatant was added to the beads (Glutathione Sepharose $4 \mathrm{~B}$, GE Healthcare) and incubated for $1 \mathrm{~h}$ at $4^{\circ} \mathrm{C}$. Beads were washed 3 times for $20 \mathrm{~min}$ and incubated with a Dsh::Myc-expressing S2 cell lysate for $2 \mathrm{~h}$ at room temperature. Beads were then pelleted and washed 3 times. The eluted proteins were analyzed by Western blot. Primary antibody was mouse $\alpha$-Myc 4A6 (1:500) (Millipore). Secondary antibody was $\alpha$-mouse-HRPO (1:5000) (DAKO).

Coimmunoprecipitation. A total of $7 \times 10^{6} \mathrm{~S} 2$ cells were lysed in FAC buffer ( $50 \mathrm{~mm}$ HEPES, $80 \mathrm{~mm} \mathrm{KCl,} 5 \mathrm{~mm} \mathrm{MgCl}_{2}, 2$ mм EGTA, $0.2 \%$ Triton $\mathrm{X}-100, \mathrm{pH}$ 7.4) containing protease inhibitor mixture (Roche) at $4^{\circ} \mathrm{C} ; 10 \mu \mathrm{l}$ of $\alpha$-Myc antibody was added to the lysate and incubated for $3 \mathrm{~h}$ at $4^{\circ} \mathrm{C}$. After centrifugation $35 \mu \mathrm{l}$ Protein-A Sepharose was added to the lysate and incubated for $1.5 \mathrm{~h}$ at room temperature. Primary antibodies were rabbit $\alpha$-Myc A-14 (Santa Cruz Biotechnology) for precipitation; mouse $\alpha$-Flag M2 (1:500) (Sigma) and mouse $\alpha$-Myc 4A6 (1:500) (Millipore) for Western blots. Secondary antibodies were $\alpha$-rabbitHRPO $(1: 10,000)$ (Sigma) and $\alpha$-mouse-HRPO (1:5000) (DAKO).

Image analysis. $\mathrm{S} 2$ cell images were acquired in a Leica SP2-AOBS point laser scanning confocal microscope using a $63 \times 1.4$ NA oil-immersion lens. Quantification for colocalization analysis was performed using the ImageJ software (National Institutes of Health) in individual frames after adjusting the thresholds. Colocalization (\%) was calculated with the JACoP plugin (Bolte and Cordelières, 2006) of ImageJ using the merged images in each case.

\section{Results}

\section{dDAAM expression in the adult brain}

To explore whether the formin DDAAM, plays a role in neuronal differentiation outside of the embryonic nervous system, we examined the expression pattern of $D D A A M$ in the larval, pupal, and adult CNSs by antibody staining. We found that $D D A A M$ displays a strong neuronal expression in every stage of development. Within the adult brain, the dDAAM protein was highly enriched over the entire neuropile region (where neurites and synapses are located), whereas it was much less abundant in the cortex (region of the cell bodies; Fig. $\left.1 A-B^{\prime}\right)$. One prominent dDAAM expression domain in the neuropile corresponds to the MBs (Fig. $1 B, B^{\prime}$ ), central brain regions involved in olfactory learning and memory (Heisenberg et al., 1985), characterized by a well-defined axonal projection pattern (scheme in Fig. 1C) (Lee et al., 1999). 

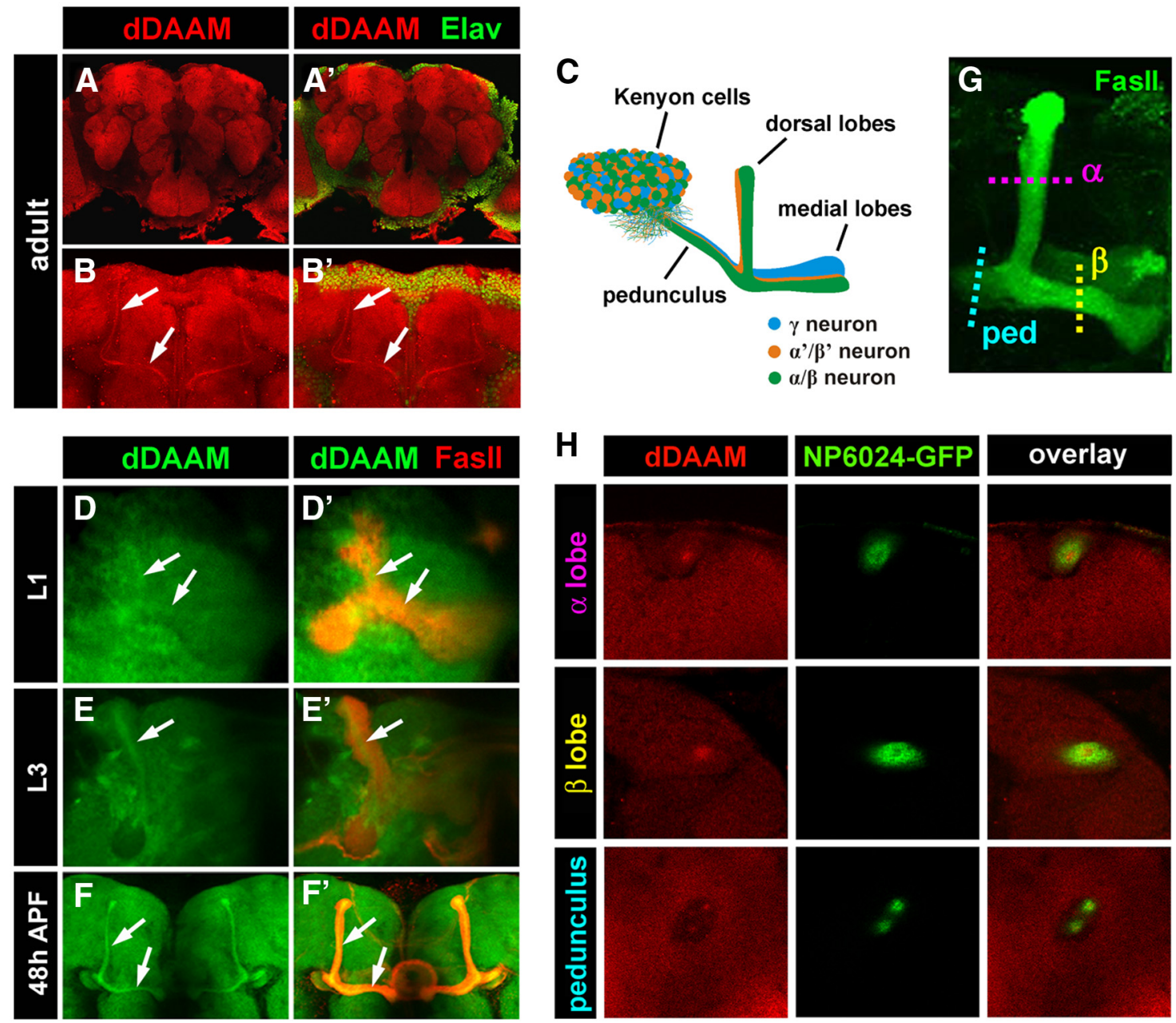

Figure 1. dDAAM protein localization in the developing brain. $A, A^{\prime}$, The dDAAM protein (red) is highly enriched in the neuropile region of the brain as shown in an optical section of a whole-mount preparation of a wild-type, few hours old adult brain. Cell nuclei are shown in green with anti-Elav staining $\left(\boldsymbol{A}^{\prime}\right) \cdot \boldsymbol{B}, \boldsymbol{B}^{\prime}$, The dDAAM protein (red) is present in the MB region of the brain where it displays a strong accumulation in the middle of the lobes (arrows). C, Schematic drawing of the MB comprised of three types of KC, the $\gamma, \alpha^{\prime} / \beta^{\prime}$, and $\alpha / \beta$ neurons (blue, orange, and green, respectively). The $\mathrm{KC}$ cell bodies are located in a dorsal posterior position, and they extend axons anterior ventrally that form a massive fiber tract called the peduncle. Whereas the $\gamma$ axons run medially and form the $\gamma$ lobe, the $\alpha^{\prime} / \beta^{\prime}$ and $\alpha / \beta$ axons bifurcate and fasciculate into the dorsally running $\alpha^{\prime}$ and $\alpha$ lobes, and the medially running $\beta^{\prime}$ and $\beta$ lobes. $\boldsymbol{D}-\boldsymbol{F}^{\prime}$, The dDAAM protein (green) can be detected in the developing $\gamma$ lobes (labeled with Fasll staining in red) during the first larval instar stage $(L 1)\left(\boldsymbol{D}, \boldsymbol{D}^{\prime}\right)$, in the $\alpha^{\prime} / \beta^{\prime}$ axons during the third larval instar stage $(L 3)\left(\boldsymbol{E}, \boldsymbol{E}^{\prime}\right)$, and in pupal brains $48 \mathrm{~h}$ after puparium formation (APF) $\left(\boldsymbol{F}, \boldsymbol{F}^{\prime}\right)$. A dDAAM enrichment is clearly visible in the middle of the MB lobes in all stages (D-F', arrows). $\mathbf{G}$, Confocal image of an MB stained with anti-Fasll (green). The $\alpha$ and $\beta$ lobes and the pedunculus are indicated, as well as the approximate position of the optical cross-sections depicted in $\boldsymbol{H}$. $\boldsymbol{H}$, Cross-sections of the $\alpha / \beta$ lobes and the pedunculus of the adult MB. The NP6024-GFP marker (green) (NP6024-Gal4/+;UAS-mCD8::GFP/+) labels the middle of the lobes where the newly forming axons run. The dDAAM protein (red) is enriched in the middle of the NP6024-GFP-positive tracts, indicating that the dDAAM accumulation corresponds to the young axons of the MB.

The MBs are composed of three types of neurons called Kenyon cells (KCs): $\gamma, \alpha^{\prime} / \beta^{\prime}$ and $\alpha / \beta$ neurons that are born in a specific temporal order (Lee et al., 1999). The $\gamma$ neurons are born during the early larval stages, the $\alpha^{\prime} / \beta^{\prime}$ neurons are born during the third larval instar (L3) stage, and the $\alpha / \beta$ neurons are born after puparium formation. Initially, the $\gamma$ neurons project in the medial and dorsal directions. However, during the early pupal stage, these axons become partially pruned and the adult $\gamma$ axons project only medially, forming the $\gamma$ lobe of the MBs (Fig. 1C). The $\alpha^{\prime} / \beta^{\prime}$ axons follow the early (unpruned) $\gamma$ axons and bifurcate to form a dorsally projecting $\alpha^{\prime}$ and a medially running $\beta^{\prime}$ lobe. Finally, the later forming $\alpha / \beta$ neurons project similarly to the $\alpha^{\prime} / \beta^{\prime}$ KCs but fasciculate into separate bundles forming the $\alpha$ and $\beta$ lobes (Fig. 1C). To assess dDAAM expression in more detail, we examined its expression from the early stages of MB development onward. dDAAM was detected in the $\gamma$ neurons already in first instar (L1) larvae, and subsequently during all larval and pupal stages (Fig. $1 D-F^{\prime}$ ).
The protein displayed strong accumulation in the central region of the developing lobes while showing weaker staining at their periphery (Fig. $1 D-F^{\prime}$ ). The consistently high dDAAM level in the core of the lobes and the peduncle of the MBs suggested that the protein is enriched in the newly projecting axons of the MBs, which are known to run in the middle of the bundles (Verkhusha et al., 2001). To confirm this, we used the NP6024-Gal4 driver line (Tanaka et al., 2008) in combination with mCD8::GFP to label the central region of the $\alpha / \beta$ lobes. In the MBs of young adults, the ADAAM protein is clearly enriched in the middle of the NP6024-positive axons (Fig. $1 G, H)$, supporting our conclusion. Together, these data established that, similar to the situation in the embryonic CNS (Matusek et al., 2008), the dDAAM protein is expressed at high levels in the developing brain and preferentially accumulates in neurites. Importantly, expression in the MBs is highest in the newly projecting axons that may indicate a role in neurite formation. 
A

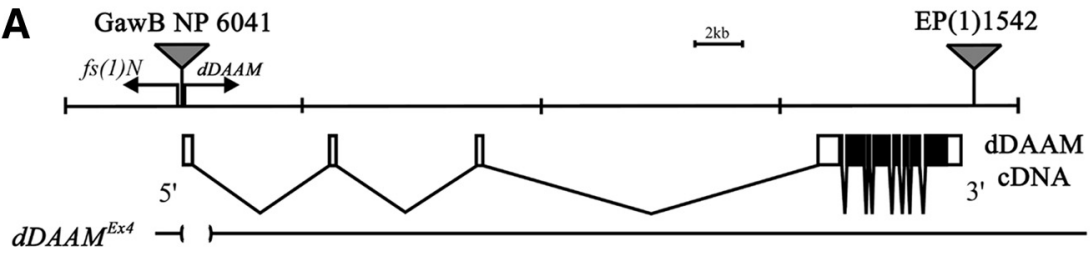

$d D A A M^{E x I}$
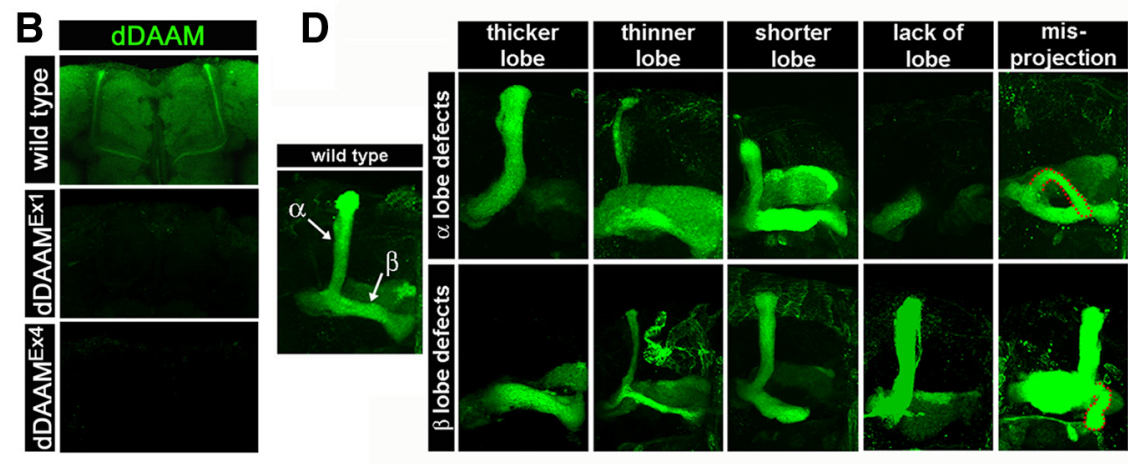

C

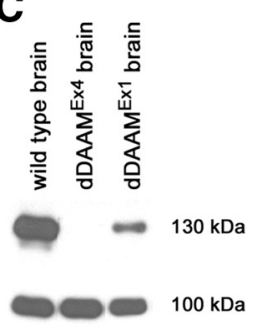

E
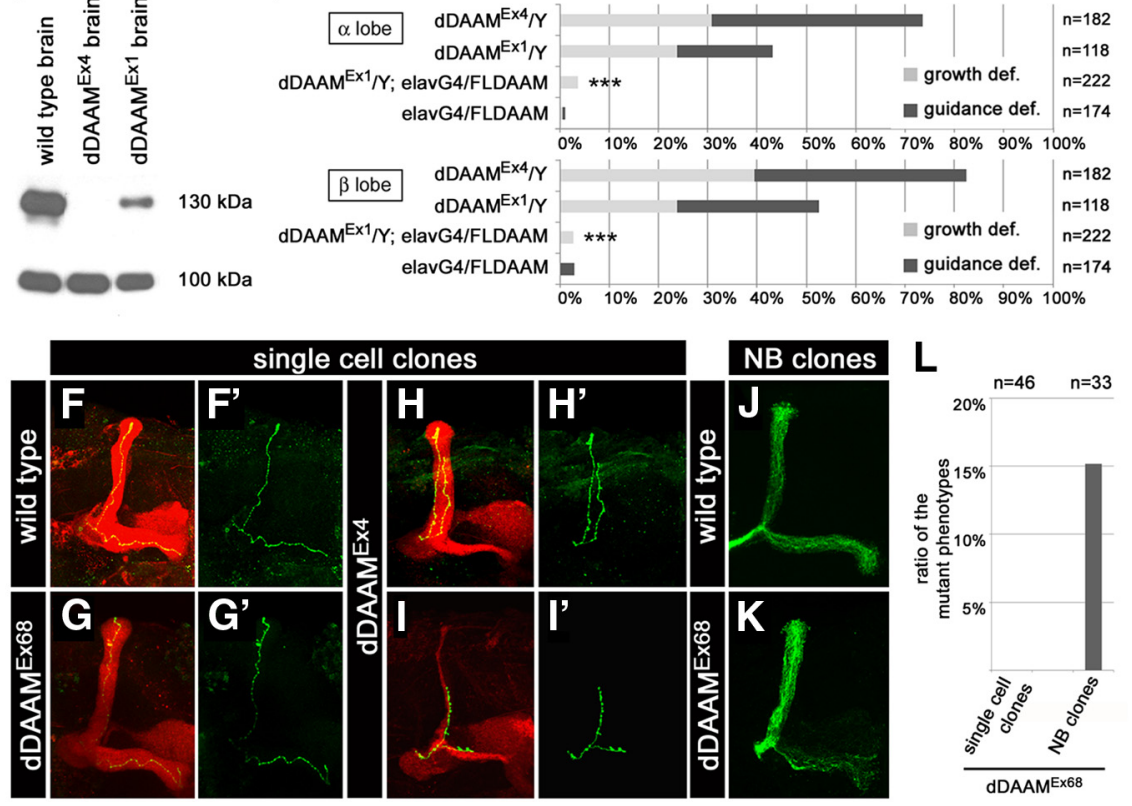

Figure 2. $\quad$ DDAAM impairs axonal development in the MB. $A$, Top, Schematic organization of the $I D A A M$ loci and exon-intron structure of a dDAAM CDNA. The P-element insertion lines, $P(G a w B) N P 6041$ and EP(1)1542, were used to create the $d D A A M^{E x 4}$ and $d D A A M^{E x x}$ excision alleles, respectively. $B$, Anti-dDAAM staining (green) of a wild-type, $D D A A M^{E x x}$ and $d D A A M^{E x 4}$ mutant brain of young adults. There is weak staining in $\triangle D A A M^{E x}$ and almost complete lack of staining in $\triangle D A A M^{E x 4}$, verifying antibody specificity. $C$, A Western blot analysis is shown with adult brain extracts from ${ }_{D} D A M^{E x 4}$ and $d D A A M^{E x]}$ mutants. The dDAAM protein can be barely detected in $\triangle D A A M^{E x}$, and it shows a highly reduced level in ${ }_{D} D A A M^{E x}$. The $130 \mathrm{kDa}$ band corresponds to the dDAAM protein, whereas the $100 \mathrm{kDa}$ band represents the loading control ( $\alpha$-glycogen phosphorylase). $\boldsymbol{D}$, The different type of axonal projection defects exhibited by the $\alpha$ and $\beta$ lobes of $A D A A M$ mutant MBs. Fasll staining (green) is used to label the lobes; a wild-type control on the left shows the dorsally running $\alpha$ lobe and the medially projecting $\beta$ lobe. $E$, Quantification of the axonal growth and guidance defects exhibited by dDAAM mutants. Data are provided separately for the $\alpha$ and $\beta$ lobes. Axonal defects can be almost fully rescued by expressing a UAS-FLDAAM construct with the pan-neuronal elav-Gal4 driver line. ${ }^{* * *} p \leq 0.0001$ (Fisher's exact test). $\boldsymbol{F}-\boldsymbol{I}^{\prime}$, Confocal images of GFP-labeled $\alpha / \beta$ single-cell clones: green represents GFP; red represents Fasll. A control single cell clone $\left(\boldsymbol{F}, \boldsymbol{F}^{\prime}\right)$ induced in a wild-type background shows the bifurcated axon with a dorsally and a medially running branch. $\mathbf{G}, \mathbf{G}^{\prime}$, A dDAAM-null mutant clone, induced in a $d D A A M^{E x 68} /+$ heterozygous background, also exhibit a wild-type axon morphology. On the contrary, MARCM clones induced in $D_{D A A M}{ }^{E x 4}$ homozygous mutants often exhibit guidance defects, most typically when both branches run in the same lobe $\left(\boldsymbol{H}, \boldsymbol{H}^{\prime}\right)$. In other cases, a growth defect is evident when the axon branches are shorter than in wild-type and fail to reach the normal target area $\left(I, I^{\prime}\right)$. The guidance and growth defects sometimes combine, such as in $\boldsymbol{H}, \boldsymbol{H}^{\prime}$, where both branches fasciculate into the dorsal lobe but one of them terminates earlier than the other $\left(\boldsymbol{H}^{\prime}\right)$. The $\alpha$ lobe in $\boldsymbol{H}$ is thicker than in wild-type; and concomitantly, the $\beta$ lobe is thinner than normal. $\boldsymbol{J}, \boldsymbol{K}$, Compared with wild-type control
dDAAM is required for growth and guidance of the $\mathrm{KC}$ axons

To address the function of $d D A A M$ during $\mathrm{MB}$ development, we examined the axonal projection pattern in $A D A A M$ lossof-function (LOF) mutants. $d D A A M$-null alleles are lethal (Matusek et al., 2006). However, the independently created $d D A A M^{E x 1}$ and $d D A A M^{E x 4}$ excision alleles (Fig. 2A) exhibit a significantly reduced DDAAM protein level in the adult brain (Fig. $2 B, C$ ) and are homozygous and hemizygous viable (Matusek et al., 2006; current study). We thus used these two hypomorphic alleles to assess the effect of reduced DDAAM levels on the structure of the MBs. We visualized the $\gamma$ and the $\alpha / \beta$ lobes with a FasII antibody in $d D A A M$ mutant young adult hemizygous males and homozygous females. Axonal projection defects were evident in the mutant MBs that were analyzed in detail in the $\alpha$ and $\beta$ lobes. The most common phenotypes included shortening, thinning, thickening or absence of the lobes, and misprojection of the axons (Fig. 2D). Shortening, thinning, and absence were classified as growth defects, whereas thickening and misprojection were classified as guidance defects (see also MARCM analysis). At $25^{\circ} \mathrm{C}$, the $\alpha$ lobes exhibited a mutant phenotype in $43 \%$ of the MBs in $d D A A M^{E x I}$ and in $74 \%$ of $d D A A M^{E x 4} \mathrm{mu}-$ tants (Fig. 2E) (unless indicated otherwise, data are shown for males because females exhibited similar defects). In case of the $\beta$ lobes, the penetrance was $53 \%$ in $d D A A M^{E x I}$ and $82 \%$ in $d D A A M^{E x 4}$ males (Fig. 2E). The occurrence of growth versus guidance defects was approximately equal in both lobes in both mutants (Fig. $2 E$ ); however, the $\beta$ lobes seemed to be somewhat more sensitive to the lack of dDAAM than the $\alpha$ lobes. By contrast, we detected no evident changes in $\mathrm{KC}$ number or dendritic organization in these mutants (data not shown). Consistent with the expression level of the remaining dDAAM protein (Fig. $2 B, C$ ), the $D D A A M^{E x 4}$ allele is clearly stronger than $D D A A M^{E x I}$, yet both alleles appeared suitable for further phenotypic characterization and genetic studies.

To verify that the MB axonal projection defects associated with $\triangle D A A M$ are

(Figure legend continued.)neuroblast (NB) clones ( $(J)$, NB clones induced in a heterozygous $d D A A M^{E x 68} /+$ mutant background and marked with mCD8::GFP (green) display an aberrant axonal morphology (note the reduced number of $\beta$ axons in $K$ ) in $15 \%$ of the cases. $L$, Quantification of the MB mutant phenotypes observed in $D_{D A A M}{ }^{E \times 68}$ mutant MARCM clones. 
A

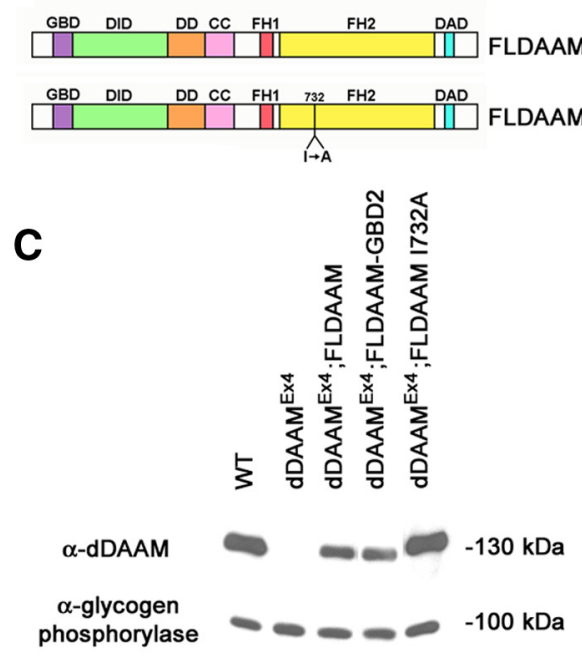

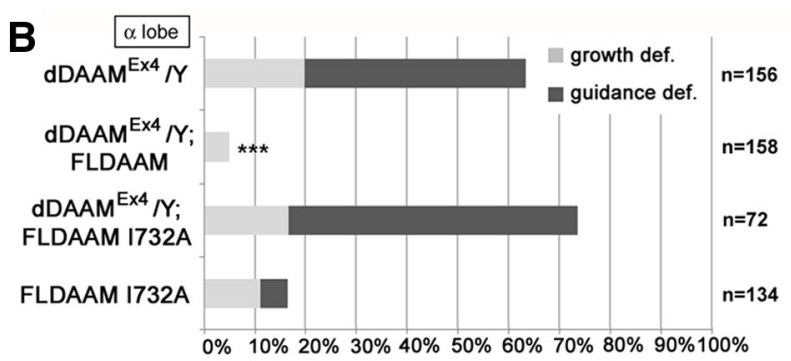

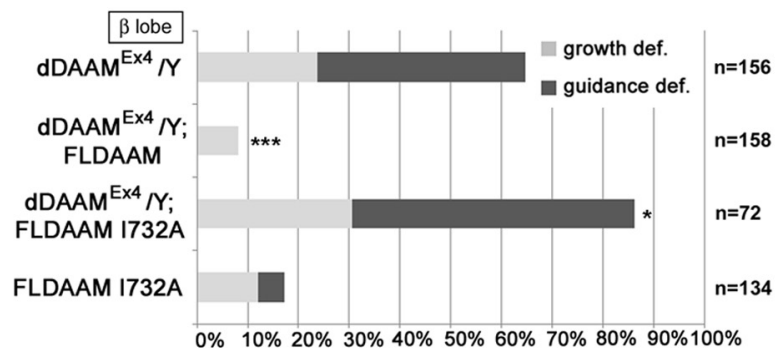

Figure 3. The actin assembling activity of dDAAM is required for axon development. $\boldsymbol{A}$, The structure of the wild-type dDAAM protein, and the position of the I732A mutation impairing actin assembly. The full-length dDAAM protein (FLDAAM) contains several conserved homology domains, including GBD (GTP-ase binding domain), DID (diaphanous inhibitory domain), DD (dimerization domain), CC (coiled-coil region), FH1 (formin homology domain 1), FH2 (formin homology domain 2), and DAD (diaphanous autoinhibitory domain). The position of the I732A (Ile ${ }^{732}$ to Ala ${ }^{732}$ ) mutation is indicated below. $\boldsymbol{B}$, Quantification of the MB axonal growth and guidance defects in DDAAM $^{\text {Ex4 }}$ mutants expressing various FLDAAM constructs. Pan-neuronal expression (elav-Gal4) of wild-type dDAAM (FLDAAM) rescues the growth and guidance defects exhibited by $D D A A M{ }^{E x 4}$ almost entirely. The FLDAAM-I732A mutant version, which is unable to promote actin assembly, fails to rescue; instead, it weakly increases the phenotypic defects, indicating a dominant negative effect; and consistently, expression of FLDAAM-I732A in a wild-type background impairs axonal development in $\sim 18 \%$ of the MB lobes. ${ }^{* * *} p \leq 0.0001$ (Fisher's exact test). ${ }^{*} 0.005<p<0.05$ (Fisher's exact test). $C$, Expression level of the $d D A A M$ transgenes used during our studies. A Western blot analysis of adult brain extracts is shown here to demonstrate that the UAS-FLDAAM, UAS-FLDAAM GBD2, and UAS-FLDAAM I732A-Flag transgenes exhibit dDAAM protein levels similar to the endogenous level when expressed pan-neuronally with elav-Gal4 in a dDAAM ${ }^{E x 4}$ mutant background. The $130 \mathrm{kDa}$ band corresponds to the dDAAM protein, whereas the $100 \mathrm{kDa}$ band represents the loading control ( $\alpha$-glycogen phosphorylase).

due to the lack of $\mathrm{DDAAM}$, rescue experiments were performed with a transgene encoding the full-length dDAAM protein (UASFLDAAM) (Matusek et al., 2006). First, we examined whether elevated DDAAM levels interfere with neuronal differentiation. We found that the neuronal overexpression of DDAAM had no effect on viability, and affected the axonal projection pattern of the $\mathrm{MB}$ in only $2 \%-3 \%$ of the cases (Fig. $2 E$ ). When driving dDAAM expression with elav-Gal4 in a $d D A A M^{E x 1}$ or $d D A A M^{E x 4}$ mutant background, the $\alpha$ and $\beta$ lobe defects were clearly rescued (Figs. $2 E, 3 B$ ), demonstrating that the $\mathrm{MB}$ phenotypes observed are specific to the loss of $\triangle D A A M$ function. Moreover, because the neuron-specific elav-Gal4 is sufficient to rescue the $d D A A M$ phenotype, these data suggest that, in agreement with its protein expression pattern, $D D A A M$ is required only in the neuronal cells of the CNS.

To gain further insights into the axonal projections errors observed at the level of the entire MBs, we used MARCM analysis (Lee and Luo, 1999) to assess the $D D A A M$-induced axonal phenotypes at single-cell resolution. To begin with, we induced clones positively marked with mCD8::GFP in a homozygous dDAAM ${ }^{E x 4}$ mutant background. Unlike wild-type control clones $(n=35)$ (Fig. $\left.2 F, F^{\prime}\right)$, each $d D A A M^{E x 4}$ mutant neuron $(n=23)$ exhibited either a guidance defect (e.g., both axon branches running into the dorsal or medial direction) or a growth defect (the formation of shorter branches than in wild-type), or sometimes a combination of the guidance and growth defects (Fig. $2 H-I^{\prime}$ ). When both mutant axon branches run in the same lobe, we always noted a concomitant thickening of this lobe paralleled with thinning of the other lobe $\left(n=11\right.$; Fig. $\left.2 H, H^{\prime}\right)$.

To extend the MARCM analysis, mCD8::GFP-marked singlecell clones $(n=46)$ were also induced in a heterozygous dDAAM $M^{\text {Ex68-null }}$ mutant (Matusek et al., 2006) background.
However, in this case, the single-cell $\mathrm{KC}$ clones displayed a wildtype morphology with a single, bifurcated axon (Fig. $\left.2 F-G^{\prime}, L\right)$. In addition to single-cell clones, we also induced large neuroblast clones $(n=33)$ that included up to $\sim 200$ neurons. Whereas wild-type control clones exhibit a normal morphology $(n=27)$ (Fig. $2 J$ ), $15 \%$ of the $d D A A M$-null mutant clones $(n=33)$ display abnormal axonal morphology in the MBs (i.e., thinning and/or thickening of the MB lobes) (Fig. $2 K, L$ ). Together with the phenotypes observed in $d D A A M^{E x 1}$ or $d D A A M^{E x 4}$ mutant brains, these results indicate that $\triangle D A A M$ has a cell-autonomous function in the MB; however, the low penetrance of the clonal phenotype may suggests that it also acts non-cell-autonomously. Another formal possibility is that $\triangle D A A M$ negatively affects cell survival and most null mutant clones die, although we think it very unlikely as the nearly protein-null $d D A A M^{E x 4}$ allele does not affect cell survival, and based on a control experiment, the rate of both single-cell and neuroblast clone production in control and dDAAM ${ }^{E x 68}$ mutant backgrounds appear similar to each other (data not shown). As a further alternative, we consider that the highly perdurant dDAAM protein (Matusek et al., 2008; Molnár et al., 2014) may provide rescue in the mutant cells that is particularly relevant in single-cell clones, but potentially even larger neuroblast clones can be rescued by low levels of the protein.

Taking the results of the whole MB and the MARCM analysis together, our LOF data suggest that DDAAM is required for both correct growth and guidance of the MB axons.

\section{The actin assembly activity of DDAAM is required for axon growth}

In vitro dDAAM behaves as a bona fide formin, possessing actin nucleation and polymerization activity (Barkó et al., 2010). Moreover, it was shown that the dDAAM protein is highly en- 

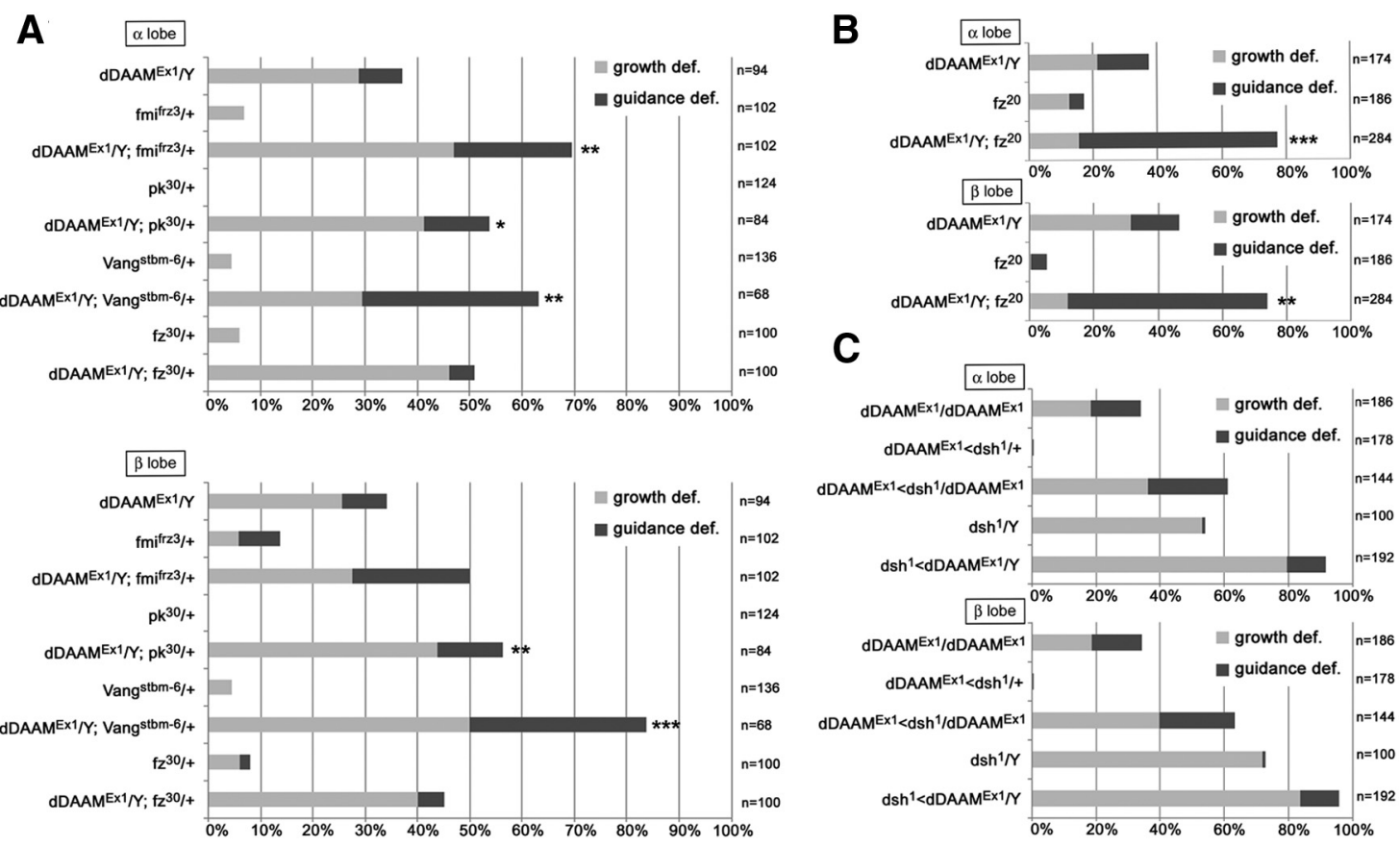

Figure 4. Genetic interaction tests with $d D A A M$ and the PCP genes. $A$, Quantification of the MB axonal growth and guidance defects in mutant combinations of $d D A A M M^{E x}$ and the core $P C P$ mutants

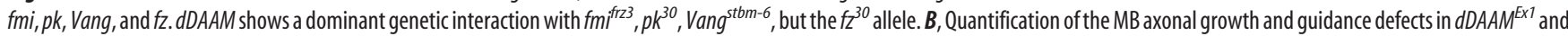
$\mathrm{fz}^{20}$ single or double homozygous mutants. The $\mathrm{dDAAM}^{\mathrm{Ex}} ; \mathrm{fz}^{20}$ double mutant displays a synergistic enhancer effect in both lobes. C, Quantification of the MB axonal growth and guidance defects in $d D A A M^{E x T}$ and $d s h^{7}$ mutant combinations. Double mutants hardly develop normal looking lobes, and dsh ${ }^{7}$ displays a strong dominant interaction with $d D A A M .{ }^{* * *} p \leq 0.0001$ (Fisher's exact test). ${ }^{* *} 0.0001<p<0.005$ (Fisher's exact test). ${ }^{*} 0.005<p<0.05$ (Fisher's exact test).

riched in the growth cone periphery of embryonic primary neurons, suggesting that it plays a role in neuronal cytoskeleton regulation in vivo (Matusek et al., 2008). To address whether dDAAM functions as a molecular effector directly involved in the regulation of the actin cytoskeleton in the $\mathrm{MB}$ in vivo, we tested an actin polymerization incompetent dDAAM mutant form (UASFLDAAM-I732A) (Fig. 3A) (Molnár et al., 2014). The I732A point mutation is equivalent to the I845A mutation of the mouse formin $\mathrm{mDia}$ and the I1431A mutation of the yeast formin Bnil, that was previously shown to disrupt actin binding and assembly in vitro (Xu et al., 2004; Harris et al., 2006; Lu et al., 2007). In contrast to wild-type dDAAM, FLDAAM-I732A failed to rescue the phenotype of the $d D A A M^{E x 4}$ mutant (Fig. $3 B$ ). When FLDAAM-I732A was expressed in a wild-type background, it impaired axonal development in $\sim 18 \%$ of the MB lobes (Fig. $3 B$ ). This may be explained by the fact that dimerization through the FH2 (Formin Homology 2) domain is absolutely necessary for formin function (Xu et al., 2004) and the catalytically inactive mutant may titrate out part of the wild-type protein pool by forming nonfunctional heterodimers. Because the FLDAAMI732A mutant isoform appears to be present in neurons at levels comparable with wild-type dDAAM (Fig. 3C), the lack of rescue is unlikely to be due to inappropriate protein levels. Thus, these results indicate that the actin nucleation and polymerization activity of dDAAM is indispensable for axonal growth regulation, and the I732A mutant form has a dominant negative effect in vivo.

dDAAM functions together with the core PCP factors and Wnt5 during axonal development of the MB

Recent work demonstrated that the Drosophila PCP proteins regulate axonal development in the MB (Shimizu et al., 2011; Ng, 2012). Flies with mutations in $f z, d s h$, Vang, or $p k$ show defects in branching and targeting of the $\mathrm{KC}$ axons, suggesting that, like their vertebrate homologs (Goodrich, 2008; Tissir and Goffinet, 2010), the PCP factors contribute to growth cone guidance in flies. Given that loss of the core PCP factors results in similar MB phenotypes as to the loss of $D D A A M$, both in homozygous mutants and in MARCM neuroblast clones where they exhibit comparably weak effects as $d D A A M(\mathrm{Ng}, 2012)$, we asked whether dDAAM functionally interacts with the PCP system during development of the MBs. To address this question, dominant genetic interaction tests were performed with $d D A A M^{E x 1}$ and mutant alleles of $f z$, Vang, $p k$, fmi, and $d s h$. Of these, $V a n g^{s t b m-6}, p k^{30}$, and $f_{m i} i^{\text {frz } 3}$ significantly enhanced the axonal projection defects of $d D A A M^{E x I}$ (Fig. 4A). Consistent with previous data (Ng, 2012), the effect of Vang was stronger in the $\beta$ lobes, whereas $f m i^{i f r z}$ strongly enhanced the $\alpha$ lobe defects (Fig. 4A). Meanwhile, $p k$ exhibited no clear specificity for either of the lobes (Fig. $4 A$ ). In the case of the $f z^{30-n u l l}$ allele, dominant interactions were not evident (Fig. 4A). However, the hypomorphic $f z^{20}$ allele displayed a synergistic enhancement in both lobes in the $d D A A M^{E x I} ; f z^{20}$, $f z^{20}$ double homozygous mutant combination (Fig. $4 B$ ), indicating a functional link between the two genes. To identify potential genetic interactions with $d s h$, we crossed $d D A A M^{E x I}$ with the viable $d s h^{1}$ allele that is known to strongly impair the noncanonical Wnt/PCP pathway but not the canonical $\mathrm{Wnt} / \beta$-catenin pathway. Heterozygosity for $d s h^{1}$ in a $d D A A M^{E x 1}$ background clearly enhanced the frequency of the MB axonal defects compared with $A D A A M^{E x I}$ homozygous females (quantified in Fig. $4 C)$. Meanwhile the $d D A A M^{E x I}, d s h^{1} /+$ double heterozygous mutants exhibited very few, if any, defects (Fig. $4 C$ ). Next, we examined the $d D A A M^{E x I}, d s h^{1}$ double hemizygous males. As a control, we used $d s h^{1}$ single hemizygous mutants that, in accordance with former studies (Shimizu et al., 2011; Ng, 2012), exhibit axonal projection defects similar to $d D A A M^{E x 1}$ in $54 \%$ of 

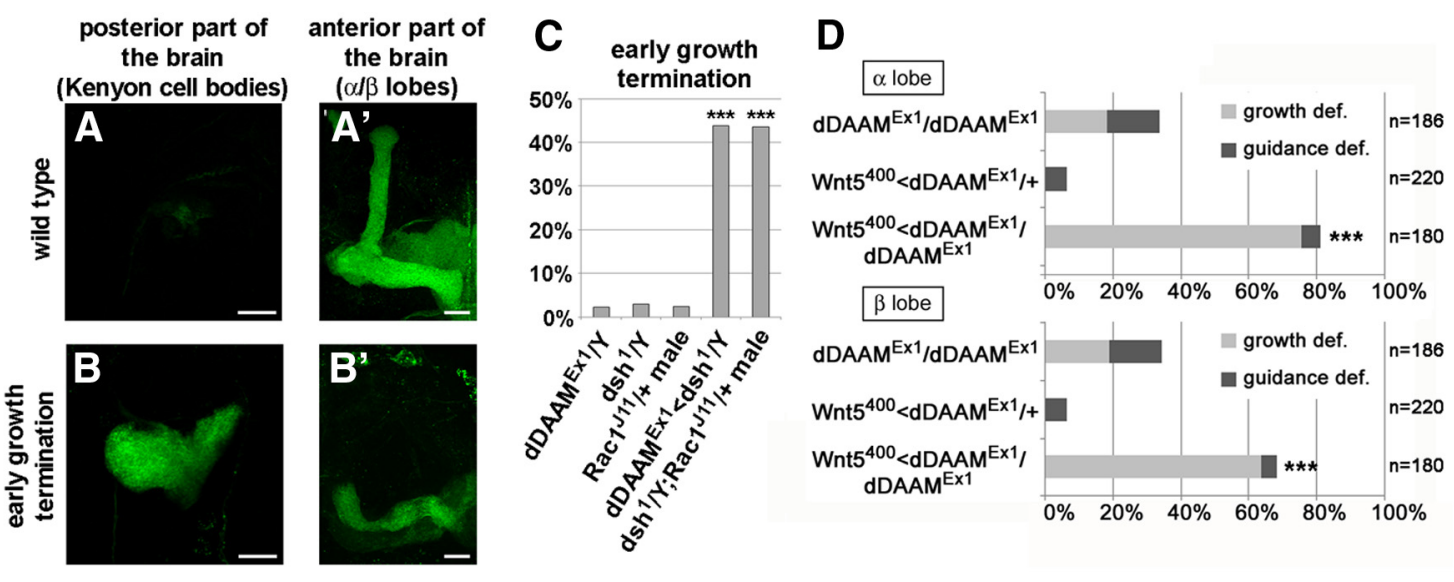

Figure 5. The early axonal growth termination phenotype of $d D A A M$, dsh, and $R a c 1$, and the genetic interaction between $d D A A M$ and $W n t 5 . A-B^{\prime}, A$ large fraction of the $d D A A M^{E x 1}<d s h^{1} / Y$ and $d s h^{1} / Y ; R a c 1^{111} /+$ mutant combinations exhibit an early axonal growth termination phenotype. Unlike in wild-type $\left(A, A^{\prime}\right)$, the mutant MB axons fail to project anteriorly; instead, they form a ball-like structure in the posterior part of the brain $\left(\boldsymbol{B}, \boldsymbol{B}^{\prime}\right)$. Fasll staining (green) was used to visualize the $\alpha / \beta$ and $\gamma$ lobes. $C$, Quantification of the early growth termination phenotype in $d D A A M^{E x}$, $d s h^{7}$, and $R a c 7^{111} /+$ single and double mutant males. The double mutants exhibit this effect in a significantly higher proportion than the single mutants. D, Quantification of the MB axonal growth and guidance defects in $D_{D A A M}{ }^{E x}$ and $W n t 5^{400}$ mutant combinations. Note the strong dominant interaction between the two alleles. ${ }^{* * *} p \leq 0.0001$ (Fisher's exact test). Bars, $20 \mu \mathrm{m}$.

the $\alpha$ lobes and $73 \%$ of the $\beta$ lobes (Fig. 4C). In comparison, the $d D A A M^{E x l}, d s h^{1}$ double mutants show abnormal $\alpha / \beta$ lobes in almost all flies tested (Fig. 4C). More importantly, careful examination of these mutants revealed that, in $43.8 \%$ of the MB hemispheres, the axons fail to project anteriorly and form a ball-like structure in the region of the KC bodies (Fig. $5 A-C$ ), whereas the occurrence of such severe early growth termination phenotypes in single mutants is very low $\left(2.32 \%\right.$ in $d D A A M^{E x l}, 3 \%$ in $d s h^{1}$; Fig. $5 C$ ). Together, these observations support the idea that the core PCP proteins act cooperatively with $\mathrm{DDAAM}$ during axonal development in the MBs.

Wnt5 mutants were shown to exhibit a similar type of $\alpha / \beta$ lobe defects as the core PCP mutants (Grillenzoni et al., 2007; Shimizu et al., 2011), and Wnt5 genetically interacts with $f z$, $d s h$ and Vang (Shimizu et al., 2011), indicating that Wnt5 may function as a ligand for the PCP pathway during MB development. Supporting this possibility, we found that $W n t 5^{400}$ is a strong enhancer of $d D A A M^{E x I}$ with respect to the $\mathrm{MB}$ axonal growth phenotypes (Fig. 5D). These results suggest that the Wnt5/PCP pathway governs actin dynamics in the growth cone by activating dDAAM, a formin directly involved in actin regulation, and supports the notion that Wnt5 acts as a PCP ligand in the MB neurons.

\section{dDAAM interacts with Dsh in a Fz-dependent manner in S2 cells}

As our genetic assays pointed toward a functional interaction between dDAAM and the PCP system, we sought to identify which PCP protein might interact with DDAAM directly. Given that the founding member of the DAAM formin subfamily was identified as a Dsh-associated protein (Habas et al., 2001), Dsh appeared a strong candidate. To assess the potential interaction of Drosophila DAAM and Dsh, a set of biochemical experiments were performed. First, we found that, unlike GST-N-DAAM (the $\mathrm{N}$-terminal portion of dDAAM), GST-C-DAAM (the C-terminal portion of dDAAM) (Fig. 6A) specifically pulled down Dsh::Myc from S2 cell lysates transfected with a Dsh::Myc-expressing construct (Fig. 6B). This result is in line with former observations demonstrating that C-DAAM but N-DAAM binds the Dsh ortholog Dvl in vertebrate systems (Habas et al., 2001; Liu et al., 2008). Surprisingly, when dDAAM or Dsh was immunoprecipitated from S2 cells transfected with dDAAM:::Flag and Dsh::Myc constructs, no association was detected between the two proteins (Fig. 6C). Consistently, dDAAM and Dsh failed to colocalize in the cytoplasm of these cells (Fig. $6 D-G^{\prime \prime}$, quantified in Fig. $6 \mathrm{M}, N$; dDAAM and Dsh mainly accumulate into cytoplasmic puncta in the double transfected cells). However, given that upon activation of the Wnt/PCP signaling module the cytoplasmic Dsh protein is recruited to the plasma membrane (Axelrod et al., 1998; Boutros et al., 2000), we assumed that the association of Dsh and DDAAM may depend on the subcellular localization of Dsh. To test this, S2 cells were triple transfected with Fz::Myc, dDAAM::HA, and Dsh::GFP constructs. As expected, the presence of $\mathrm{Fz}$ induced the translocation of Dsh to the membrane (Fig. 6I,J), and strikingly dDAAM also showed a marked membrane accumulation and colocalization with both $\mathrm{Fz}$ and Dsh (Fig. 6I-L, quantified in Fig. $6 M, N$ ). In addition, in the presence of $\mathrm{Fz}$, dDAAM was coimmunoprecipitated with Dsh from triple transfected S2 cell lysates (Fig. 6C). As a control, we also examined Fz and dDAAM double transfected cells in which Fz was found to be largely membrane-associated, while dDAAM remained mainly cytoplasmic; therefore, only a weak colocalization was detected (Fig. $6 \mathrm{H}-\mathrm{H}^{\prime \prime}$, quantified in Fig. $6 M, N$ ). These data demonstrate that, at least in S2 cells, Fz-dependent membrane recruitment of Dsh is required for the formation of a Dsh-dDAAM complex, and Fz alone does not bind DDAAM. Collectively, the genetic interaction and biochemical assays strongly suggest that the Drosophila Dsh and DAAM proteins act concertedly to promote growth and proper navigation of the $\mathrm{MB}$ axons.

Given that the putative Fz ligand, Wnt5, was shown to be expressed in S2 cells (Petrova et al., 2013), we next asked whether the Fz-dependent membrane recruitment and association of Dsh and DDAAM depend on Wnt5. We found that upon silencing of Wnt5, Fz is still able to recruit Dsh to the cell membrane (Fig. 6O), where Dsh can interact with dDAAM in the presence of Fz, even in the absence of Wnt5 (Fig. 6C). Hence, Wnt5 does not appear to be critical for activation of $\mathrm{Fz}$ when $\mathrm{Fz}$ is overexpressed in S2 cells (presumably due to the presence of other ligands or a ligandindependent activation mechanism), and Wnt5 is not a specific activator of Dsh/dDAAM association in this model system. Although these observations argue against Wnt5 playing an impor- 
A

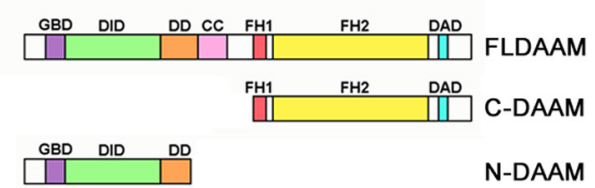

B

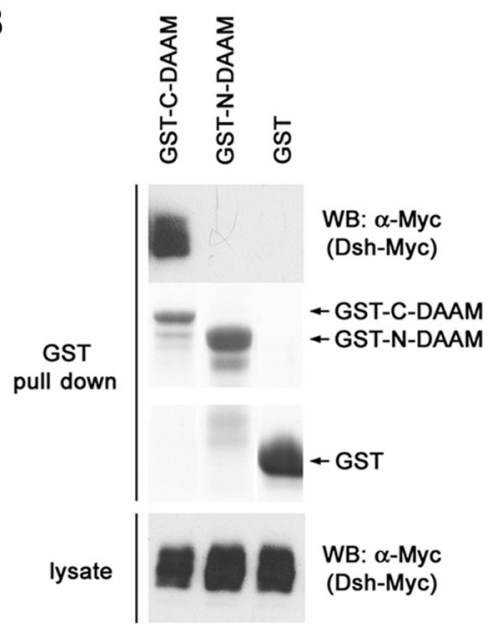

C

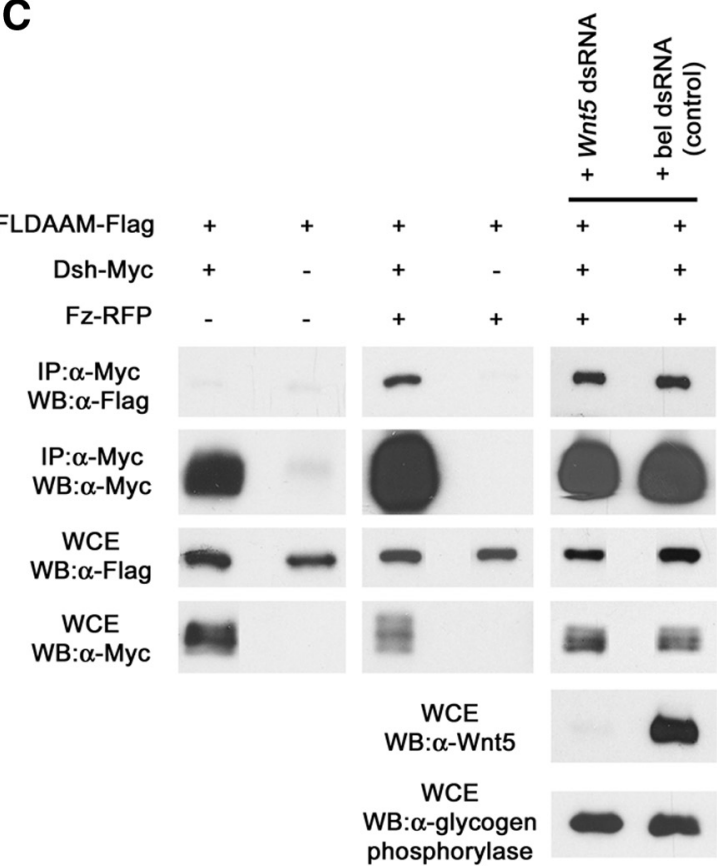

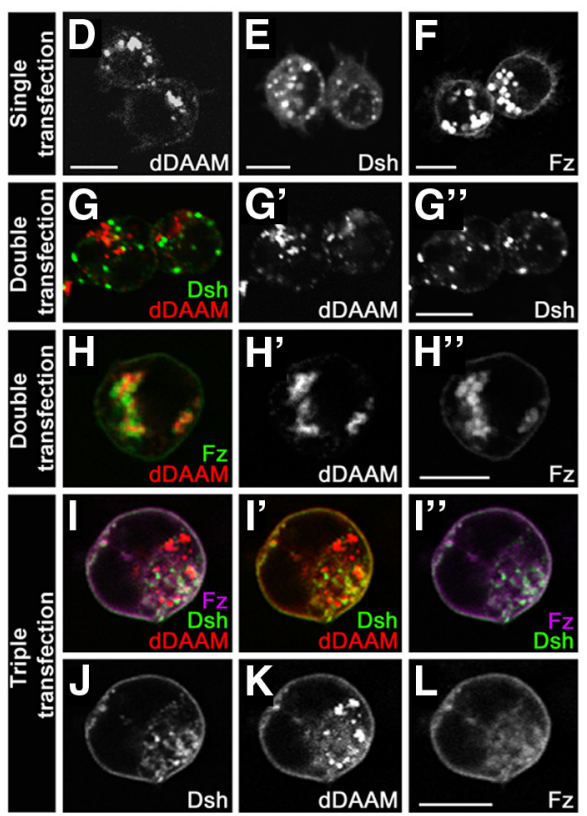
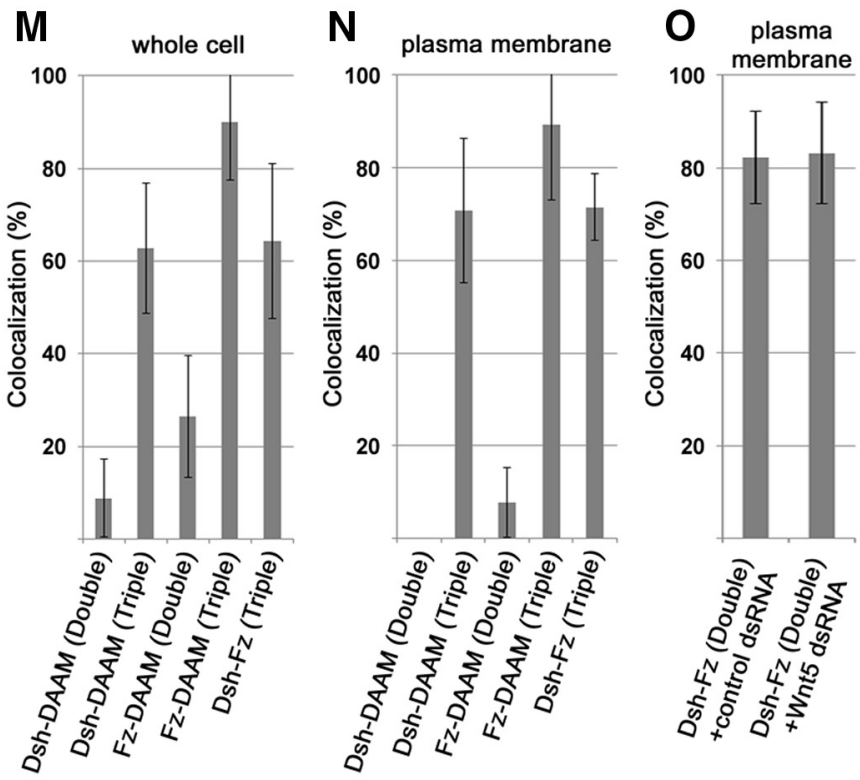

Figure 6. Fz promotes the formation of membrane-associated Dsh-dDAAM complexes. $A$, The structure of the wild-type dDAAM protein and the truncated C-DAAM and N-DAAM isoforms used during our GST pull-down experiments. B, GST pull-down assay with truncated dDAAM isoforms. C-DAAM pulled down Dsh-Myc from S2 cell lysates, whereas N-DAAM did not. C, Coimmunoprecipitation experiment with dDAAM-Flag and Dsh-Myc double transfected, or dDAAM-Flag, Dsh-Myc, and Fz-RFP triple transfected S2 cells. dDAAM-Flag was coprecipitated with Dsh-Myc only in the presence of Fz-RFP, and this interaction is independent of the presence of Wnt5 (silencing with the bel dsRNA was used as a control; $\alpha$-glycogen phosphorylase was used as loading control). WB, Western blot; WCE, whole-cell extract. $\boldsymbol{D}-\boldsymbol{L}$, S2 cells transfected with dDAAM-HA (D), Dsh-GFP $(\boldsymbol{E})$, or Fz-Myc $(\boldsymbol{F})$ alone, or cotransfected with dDAAM and Dsh $\left(\boldsymbol{G}-\boldsymbol{G}^{\prime \prime}\right)$, dDAAM and Fz $\left(\boldsymbol{H}-\boldsymbol{H}^{\prime \prime}\right)$, or triple transfected with dDAAM, Dsh, and Fz $(\boldsymbol{I}-\boldsymbol{L})$. In the case of single transfections, stained for the corresponding protein tag, dDAAM-HA (D) and Dsh-GFP (E) localize mostly in the cytoplasm, whereas Fz-Myc $(\boldsymbol{F})$ displays a cytoplasmic and a plasma membrane accumulation as well. In the double transfected cells, neither Dsh nor Fz shows strong colocalization with dDAAM $\left(\mathbf{G}-\boldsymbol{H}^{\prime \prime}\right)$. By contrast, in triple transfected cells, beyond a partial cytoplasmic accumulation, all three proteins show a membrane accumulation and a strong colocalization with each other $\left(I-I^{\prime \prime}\right)$. $J-L$, Individual channels of a triple transfected cell. $\boldsymbol{M}, \boldsymbol{N}$, Quantification of the colocalization between Dsh, dDAAM, and Fz (in the pairwise combinations indicated) in the whole cell $(\boldsymbol{M})$ or at the plasma membrane $(\boldsymbol{N})$ in double (Dsh-DAAM or Fz-DAAM) or triple (Dsh-DAAM-Fz) transfected S2 cells. 0, Quantification of the colocalization between Dsh and Fz at the plasma membrane in the presence of a control dsRNA, and the Wnt5 dsRNA that strongly reduces the Wnt5 protein level (see also $\mathbf{C}$ ). $\mathbf{M - \mathbf { O }}$, Error bars indicate the SD. Scale bars, $10 \mu \mathrm{m}$.

tant role in Fz/PCP activation, signaling specificity and outcome can be largely different in vivo than in cell cultures; thus, we can by no means exclude the possibility that Wnt 5 contributes to $\mathrm{Fz} / \mathrm{PCP}$ signaling in the MB neurons.
dDAAM functions downstream of Dsh in MB neurons

Dsh is thought to function downstream of $\mathrm{Fz}$ during tissue polarity signaling (Adler, 2002; Mihály et al., 2005); however, the position of dDAAM with regard to the PCP regulatory hierarchy 

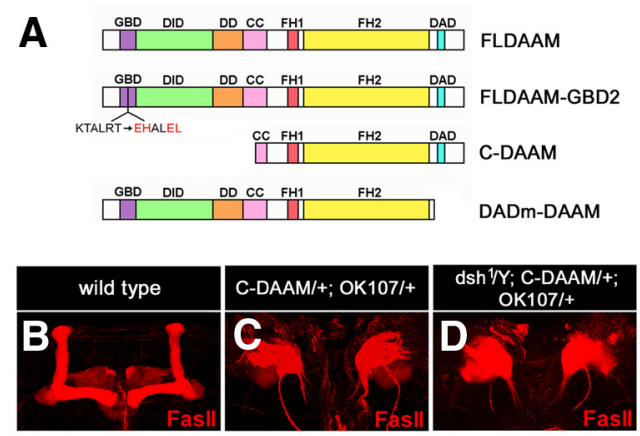

E

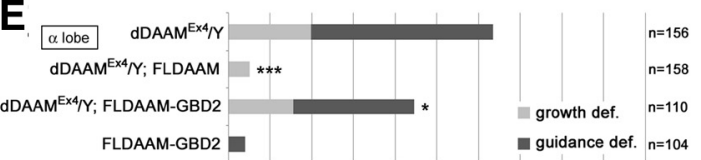
$\begin{array}{llllllllllllll}0 & 0 \% & 10 \% & 20 \% & 30 \% & 40 \% & 50 \% & 60 \% & 70 \% & 80 \% & 90 & 100 \%\end{array}$

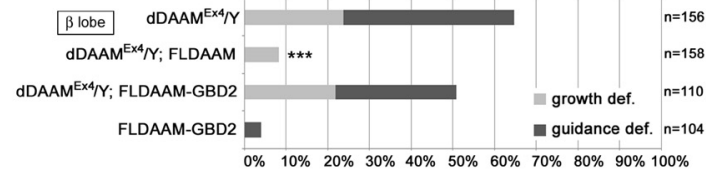

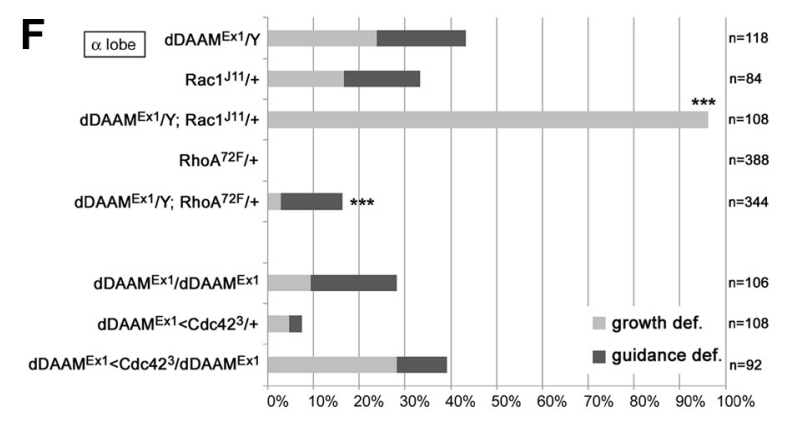

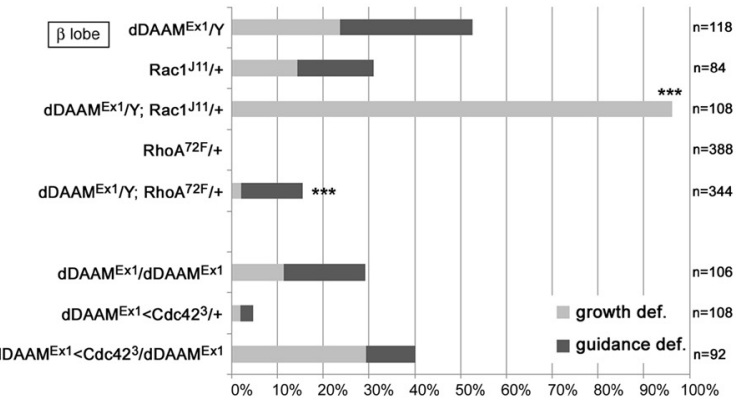

Figure 7. The mechanisms of dDAAM activation. $A$, The structure of the wild-type and GBD2 mutant (Lys ${ }^{144} \mathrm{Thr}^{145}$ to $\mathrm{Glu}^{144} \mathrm{His}^{145}$, and $\mathrm{Arg}^{148} \mathrm{Thr}^{149}$ to $\mathrm{Glu}^{148}$ Leu ${ }^{149}$ ) dDAAM proteins, and that of the C-DAAM and DADm-DAAM isoforms. $\boldsymbol{B}-\boldsymbol{D}$, Compared with a wild-type MB (B), OK107-Gal4-driven overexpression of the constitutively active dDAAM isoform (C-DAAM) induces severe axonal growth and guidance defects, resulting in the formation of a large, randomly oriented network of projections in the posterior brain region (C). Very similar effects are seen when C-DAAM is expressed in a $d s h^{7}$ mutant background (D). Fasll staining (red) was used to visualize the $\alpha / \beta$ and $\gamma$ lobes in $\boldsymbol{B}-\boldsymbol{D}$. E, Neuronal expression (elav-Gal4) of wild-type dDAAM (FLDAAM) rescues the growth and guidance defects exhibited by DDAAM $^{E x 4}$, whereas FLDAAM-GBD2, a mutant version with impaired GTPase binding, provides only a partial rescue in both lobes. The overexpression of FLDAAM-GBD2 in a wild-type background causes a negligible axonal guidance phenotype. $F$, Quantification of the MB axonal growth and guidance defects in mutant combinations of $d D A A M{ }^{E x T}$ and $R a c 1^{111}, R_{h o A^{72 F}}$ and $C d c 42^{3}$. There is a dominant enhancer effect of $R a c 1^{111}$ in both lobes. ${ }^{*} 0.005<p<0.05,{ }^{* * *} p \leq 0.0001$ (Fisher's exact test).

in $\mathrm{MB}$ neurons remained unclear. To address this question, an epistasis analysis was performed, using an activated dDAAM isoform. Members of the DRF (Diaphanous Related Formin) family, such as DAAM, are regulated by an autoinhibitory mechanism via an intramolecular interaction between the $\mathrm{N}$-terminal and extreme C-terminal autoinhibitory domains (Wallar and Alberts, 2003). This interaction is thought to hinder the actin assembling activity provided by the highly conserved FH1 and FH2 domains. Removal of the inhibitory regions results in formin activation, and we have shown previously that C-DAAM, a truncated isoform of dDAAM lacking the N-terminal autoinhibitory domains (Fig. 7A), behaves as a constitutively active formin when expressed in the embryonic CNS (Matusek et al., 2008). Here we found that OK107-Gal4-driven overexpression of $U A S-C-D A A M$ induces very severe growth and guidance defects in the $\mathrm{MB}$ axons. Most notably, unlike in wildtype (Fig. $7 B$ ), these axons fail to project anteriorly and form a huge unstructured, randomly oriented network of projections with very prominent but misprojected bundles in the posterior region of the brain (Fig. $7 C$ ). This phenotype is consistent with C-DAAM acting as an unregulated formin, promoting actin assembly in an uncoordinated manner and thereby preventing directed growth cone motility. When we addressed whether this C-DAAM induced gain-of-function phenotype was dependent on the presence of functional Dsh proteins, we found that the $d s h^{1}$ mutation had no effect on the axonal growth defects generated by C-DAAM overexpression (Fig. 7D). Therefore, this analysis indicated that Dsh is likely to act upstream of DDAAM in the MB neurons, which is consistent with vertebrate studies demonstrating that the mammalian and Xenopus Daam proteins function downstream of Dvl proteins in the PCP pathway (Habas et al., 2001; Liu et al., 2008).

\section{dDAAM is activated by Dsh and Rac1}

Although binding to Dsh might be critical to the correct spatial and temporal regulation of dDAAM activity, previous work established that DRF family formins are regulated by Rho GTPases. Most relevantly, we found that DDAAM is regulated by Rac GTPases but not RhoA and Cdc42 during embryonic CNS development (Matusek et al., 2008). Therefore, we examined whether GTPase binding is important for dDAAM function in the MB neurons. To this end, we mutated the GTPase binding domain (GBD) of dDAAM in the same way as published for hDaam 1 (Ang et al., 2010) (see also Materials and Methods), and assessed the mutant transgene (UAS-FLDAAM-GBD2) (Fig. 7A) in rescue experiments. Neuronal expression of UAS-FLDAAM-GBD2 in a dDAAM ${ }^{E x 4}$ mutant background barely rescued the $\mathrm{MB}$ axonal defects (18.91\% rescue in the $\alpha$ lobes and $14.75 \%$ in the $\beta$ lobes) (Fig. $7 E$ ). This observation suggested that binding of a Rho family GTPase is important for dDAAM function in the context of MB development. To determine which GTPase may act together with dDAAM, we tested mutations affecting the Drosophila members of the Rho GTPase family in a dominant genetic interaction assay. Similarly to embryonic neurons, heterozygosity for Racl strongly enhanced the axonal growth defects of $d D A A M^{E x 1}$ (Fig. $7 F$ ), whereas $R a c 2, M t l, R h o A$, and $C d c 42$ did not significantly increased them (Fig. 7F; and data not shown). Collectively, these data indicate that Racl is a crucial regulator of DDAAM function in the MB neurons. Additionally, because the impairment of Racl binding severely but not entirely abolished the activity of dDAAM, we conclude that Rac1 is likely the major but not the only activator of dDAAM.

Given that DDAAM acts downstream of Dsh in the MB neurons, and vertebrate studies revealed that Dvl proteins activate Daam 1 by alleviating the autoinhibitory mechanism through 

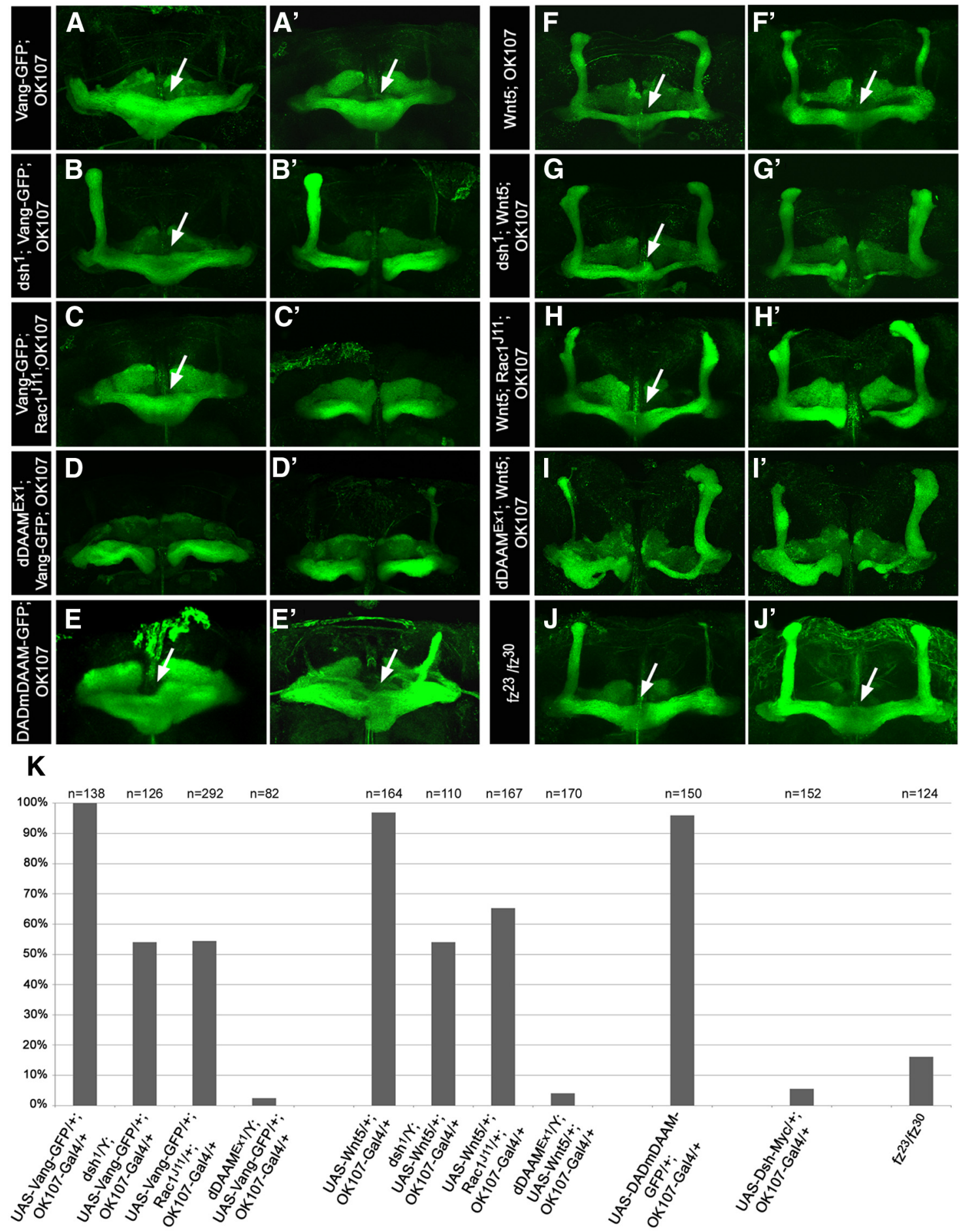

Figure 8. Mutations of $d D A A M, d s h$, and Rac1 suppress the ML fusion phenotype induced by Wnt5 or Vang overexpression. $A-J^{\prime}$, Confocal images of MBs stained for Fasll (green), two representative examples are shown for each genotype. MB-specific (OK107-Gal4) overexpression of Vang-GFP $\left(\boldsymbol{A}, \boldsymbol{A}^{\prime}\right)$, Wnt5 $\left(\boldsymbol{F}, \boldsymbol{F}^{\prime}\right)$, activated dDAAM (DADm-DAAM-GFP) (E, $\left.\boldsymbol{E}^{\prime}\right)$, or a loss of $f z$ function $\left(J, J^{\prime}\right)$, in addition to various effects on the dorsal lobes, results in overprojection of the ML axons that lead to an ML fusion phenotype (indicated by arrows). The ML fusions induced by Vang or Wnt5 are partly suppressed in a dsh ${ }^{7}$ mutant background $\left(\boldsymbol{B}, \boldsymbol{B}^{\prime}, \mathbf{G}, \mathbf{G}^{\prime}\right)$ and by $R a c 7^{111} /+\left(\boldsymbol{C}, \boldsymbol{C}^{\prime}, \boldsymbol{H}, \boldsymbol{H}^{\prime}\right)$, whereas the ${ }_{D} D A M^{E \times 1}$ mutant nearly completely suppresses the overextension of the medial axons $\left(\boldsymbol{D}_{\boldsymbol{D}}, \boldsymbol{D}^{\prime}, \boldsymbol{I}, \boldsymbol{I}^{\prime}\right)$. $\boldsymbol{K}$, Quantification of the ML fusion phenotype of the genetic combinations indicated. Unlike LOF for $\mathrm{fz}, \mathrm{GOF}$ for Vang, Wnt5 or dDAAM has equally strong, high penetrance effect that is reduced to $\sim 55 \%$ by $d s h^{7}$ or $R a c 1^{111} /+$, and almost entirely by $d D A A M^{E x T}$.

binding to the C-terminal autoinhibitory domain of Daam1 (Liu et al., 2008), Dsh is a strong candidate for being also involved in dDAAM activation. If Racl and Dsh are both required for dDAAM activation, we predict that the $d s h^{1}$ phenotype is sensitive to Rac1 level, similarly to the lack of dDAAM. Indeed, unlike $d s h^{1}$ alone, the $d s h^{1} / Y ; \operatorname{Racl}^{J 11} /+$ mutant combination displays a strong early axonal growth termination phenotype that is nearly identical to the $d D A A M^{E x l}, d s h^{1} / Y$ double mutants (Fig. $5 A$ ). Together, these observations are in accordance with the view that, in vivo, the autoinhibited IDAAM protein is activated by Rac1 binding to the GBD domain and Dsh binding to the DAD domain. 

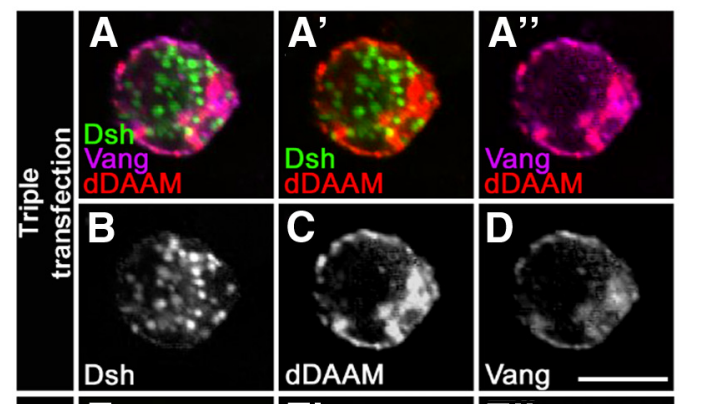

G

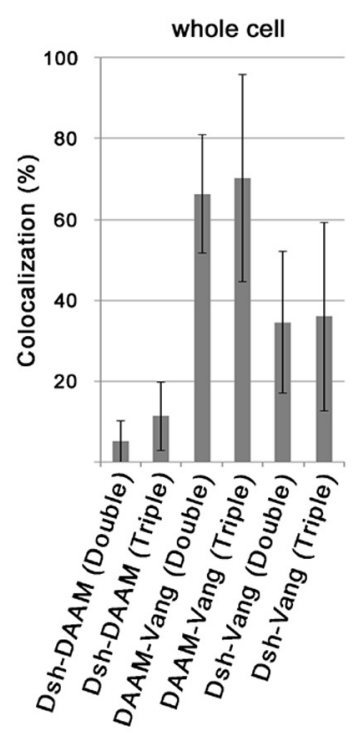

H

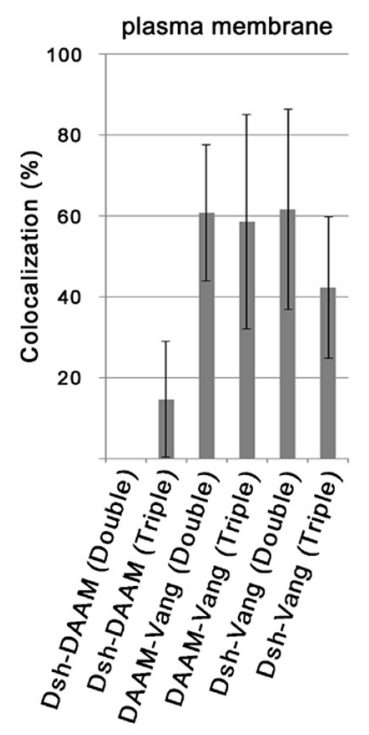

Figure 9. The colocalization of Vang and dDAAM in S2 cells. $A-\boldsymbol{F}^{\prime \prime}$, Confocal images of $S 2$ cells triple transfected with Vang-Flag, dDAAM-HA, and Dsh-GFP (A-D) or cotransfected with Vang-Flag and Dsh-GFP $\left(\boldsymbol{E}-\boldsymbol{E}^{\prime \prime}\right)$ or Vang-Flag and DDAAM-HA $\left(\boldsymbol{F}-\boldsymbol{F}^{\prime \prime}\right)$. Vang was detected with anti-Flag, DDAAM with anti-HA, and Dsh with anti-GFP staining. $\boldsymbol{A}-\boldsymbol{D}$, In triple transfected cells, the presence of Vang (magenta) does not enhance the colocalization between Dsh (green) and dDAAM (red) $\left(\boldsymbol{A}^{\prime}\right)$, but dDAAM and Vang colocalize strongly $\left(\boldsymbol{A}^{\prime \prime}\right)$. $\boldsymbol{B}-\boldsymbol{D}$, The corresponding individual channels for a triple transfected cell. $\boldsymbol{E}-\boldsymbol{E}^{\prime \prime}$, In double transfected cells, Vang (red) displays a partial colocalization with Dsh (green) that is stronger at the plasma membrane than in the cytoplasm. The corresponding individual channels are shown in $\boldsymbol{E}^{\prime}, \boldsymbol{E}^{\prime \prime}$ in grayscale. $\boldsymbol{F}-\boldsymbol{F}^{\prime \prime}$, Similar to triple transfected cells, dDAAM (red) shows a strong colocalization with Vang (green) in double transfected cells as well, both at the plasma membrane and in the cytoplasm. The corresponding individual channels are shown in $\boldsymbol{F}^{\prime}, \boldsymbol{F}^{\prime \prime}$ in grayscale. $\mathbf{G}, \boldsymbol{H}$, Quantification of the colocalization between Vang, dDAAM, and Dsh (in the pairwise combinations indicated) in the whole cell $(\boldsymbol{G})$ or at the plasma membrane $(\boldsymbol{H})$ in double (Dsh-DAAM, Vang-DAAM, or Vang-Dsh) or triple (Dsh-DAAM-Vang) transfected S2 cells. $\mathbf{G}, \boldsymbol{H}$, Error bars indicate the SD. Scale bars, $10 \mu \mathrm{m}$.

dDAAM is controlled by Wnt5 and Vang in the $\beta$ lobes Previous work revealed that $d s h$ and $p k$ mutants show no lobespecific effects, but $f z$ mutants exhibit a predominant loss of dorsal branch extensions, whereas Vang mutants preferentially lose the medial branches of the $\mathrm{MB}(\mathrm{Ng}, 2012)$. Given that the dDAAM mutants exhibit no clear lobe specificity, a dDAAM contribution seems essential to axon development in both MB lobes. In view of our data with regard to Fz/Dsh/dDAAM interactions, the strong $f z$ requirement in the $\alpha$ lobes can be explained by assuming that $\mathrm{Fz}$ promotes dorsal branch extension by activating dDAAM through Dsh and Racl. By contrast, $f z$ plays a negligible role in the $\beta$ lobes; instead, $\beta$ lobe development appears to be controlled by Vang and Wnt5. Thus, we addressed the question whether dDAAM is linked to Vang and Wnt5 during medial lobe (ML) formation.

It is known that, upon MB-specific overexpression of Vang or Wnt5, the $\beta$ lobe axons fail to terminate properly at the CNS midline and display a ML fusion phenotype (Fig. $8 A, A^{\prime}, F, F^{\prime}$, arrow; quantified in Fig. 8K) (Grillenzoni et al., 2007; Ng, 2012). We noticed that expression of an activated form of dDAAM, lacking the C-terminal DAD domain (UAS-DADm-DAAM::EGFP) (Fig. 7A) (Matusek et al., 2008), also caused an ML fusion phenotype in addition to thinner or missing dorsal lobes (Fig. $8 E, E^{\prime}, K$; this activated form has a weaker phenotypic effect than C-DAAM, which almost completely abolishes neurite formation). To test whether Wnt5 and Vang signal through DDAAM in this context, we examined the effect of Wnt5 and Vang overexpression in a dDAAM mutant background. $d D A A M^{E x I}$ almost completely suppressed the overextension of the $\beta$ lobe neurons caused by excess Wnt5 or Vang (Fig. 8D, $D^{\prime}, I, I^{\prime}, K$ ), suggesting that dDAAM is a major cytoskeletal effector of Wnt 5 and Vang in the MLs.

Although, in contrast to Wnt5 or Vang overexpression, excess of Dsh (UAS-Dsh/+; OK107-Gal4/+) rarely caused ML fusion (in $5.5 \%$ of the lobes) (Fig. $8 K$ ), LOF analysis clearly revealed a $d s h$ requirement during $\beta$ lobe development (Fig. $4 C$ ). In addition, our data indicated that Dsh and Racl are required for dDAAM activation during MB development, and thus we asked whether Dsh and Racl are required for the Wnt5- or Vanginduced ML fusion phenotype. The $d s h^{1}$ mutation partially (in $\sim 45 \%$ of the cases) suppressed the occurrence of the ML fusions typical for Wnt5 and Vang overexpression (Fig. $8 B, B^{\prime}, G, G^{\prime}, K$ ). Likewise, the Racl ${ }^{\text {J11-null }}$ mutation also exhibited a comparable partial suppression (Fig. $8 C, C^{\prime}, H, H^{\prime}, K$ ). Together, these results indicated that Rac1, Dsh, and DDAAM act downstream of Wnt5 and Vang in the $\beta$ lobes.

We then tested whether Vang, similar to Fz, promotes the association of Dsh and dDAAM. S2 cells were triple transfected with Vang::Flag, dDAAM::HA, and Dsh::GFP constructs, and protein localization was compared with the corresponding double transfections (Vang-dDAAM, Vang-Dsh, Dsh-dDAAM). We found that, unlike $\mathrm{Fz}$, the presence of Vang does not significantly enhance the colocalization between Dsh and dDAAM (Fig. 9A-D). Conversely, Dsh exhibits a partial colocalization with Vang (both in triple and double transfected cells; Fig. $9 E-E^{\prime \prime}$, quantified in Fig. $\left.9 G, H\right)$ that is stronger at the cell membrane than in the cytoplasm. Remarkably, dDAAM also shows a strong colocalization with Vang at the plasma membrane and also intracellularly, independent of the presence of Dsh (Fig. $9 A-D, F-H$ ). Thus, these data revealed that Vang by itself is not sufficient to promote the Dsh-DAAM binding in S2 cells, but unexpectedly, Vang is able to associate with dDAAM.

Together, our results suggest that Racl, Dsh, and DDAAM are common elements of a dorsal lobe-specific Fz-dependent guidance pathway and a Vang-dependent ML-specific guidance system, which implies that Dsh and DDAAM are able to participate in two 


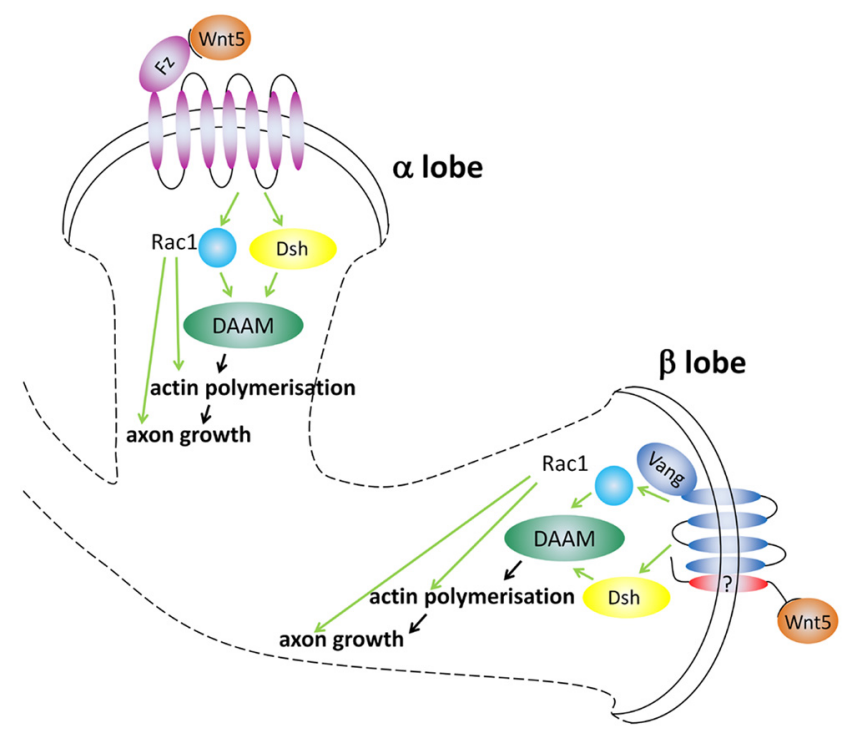

Figure 10. Hypothetic model for PCP signaling during axon growth in the MB. In $\alpha$ lobes, axon branch extension appears to be controlled by the Fz receptor, which presumably perceives a Wnt signal. Once activated, Fz recruits Dsh, and potentially Rac1, which will both contribute to the activation of the formin dDAAM, a cytoskeletal effector element involved in filopodial actin polymerization. In the $\beta$ lobes, Wnt5 and Vang cooperate, most likely through an as yet unidentified coreceptor, to promote $\beta$ lobe extension by signaling to the same or a similar Dsh/ Rac1/dDAAM module that is at work in the growth cone of the dorsally running axons. Thus, we propose that Dsh, Rac1, and dDAAM form the core of a common effector system, which is used by both the dorsal and ML-specific guidance cues to direct changes of the actin cytoskeleton in the growth cone of the MB axons.

types of PCP protein complexes and integrate at least two different navigation signals.

\section{Discussion}

Here we have shown that the formin dDAAM plays an important role in the regulation of axonal growth and guidance of the Drosophila MB neurons. Several lines of evidence suggest that dDAAM acts in concert with Wnt5 and the core PCP proteins to ensure correct targeting of the KC axons. We found that DDAAM functions downstream of Dsh and Rac1, and its ability to promote actin assembly is absolutely required for neural development in the MB. These data suggest a simple model in which axon guidance cues, such as Wnt5, signal through the PCP pathway to activate $\mathrm{dDAAM}$ to control actin filament formation in the neuronal growth cone. Thus, PCP signaling appears to be linked to cytoskeleton regulation in a direct way, and our results provide compelling experimental evidence suggesting that, at least in neuronal cells, the major cellular target of PCP signaling is the actin cytoskeleton.

Formins are highly potent actin assembly factors that are under tight regulation in vivo. The major mechanism of controlling the activity of the DRF subfamily involves an intramolecular autoinhibitory interaction between the N-terminal DID and the C-terminal DAD domains (Wallar and Alberts, 2003; Chesarone et al., 2010). This inhibition can be relieved upon binding of an activated Rho family GTPase that interacts with the GBD/DID region and also by proteins that bind to the DAD domain. Consistently, we found that the Rac1 GTPase and the DAD domain binding Dsh protein both play role in dDAAM activation in MB neurons. With this regard, it is notable that, despite that $d s h^{1}$ is considered a PCP-null allele (Axelrod et al., 1998; Boutros et al., 1998), the $d D A A M^{E x 1}, d s h^{1}$ double hemizygous mutants exhibit a stronger MB phenotype than $d s h^{1}$ mutants alone (Fig. 5A), suggesting that dDAAM must receive Dsh-independent regulatory inputs for which $\mathrm{Rac} 1$ is a prime candidate. Although previous work indicated that Rho GTPases might function downstream of Dsh in a linear pathway (Fanto et al., 2000; Habas et al., 2003), our data suggest that Dsh and Racl act in parallel pathways in the MB. As the impairment of GTPase binding severely, but not completely, abolishes dDAAM activity, we conclude that Rac1 is likely to have a stronger contribution to dDAAM activation in vivo; nonetheless, the simultaneous binding of Dsh appears to be required for full activation.

Presumably, the most remarkable feature of the PCP system relies in its ability to create subcellular asymmetries (Adler, 2002; Mihály et al., 2005; Goodrich and Strutt, 2011). Therefore, it is a tempting idea that, upon guidance signaling, the PCP proteins are involved in the generation of molecular asymmetries within axonal growth cones, yet recent attempts failed to reveal such polarized distributions in $\mathrm{MB}$ neurons ( $\mathrm{Ng}, 2012)$. Interestingly, however, it was shown that $\mathrm{Fz}$ and Vang display a differential requirement during development of the MBs, with Fz predominantly acting in the dorsal lobes and Vang predominantly acting in the MLs (Ng, 2012). We found that, in contrast to Fz and Vang, dDAAM plays a crucial role in both lobes of the MBs. Additionally, we demonstrated that Fz promotes the formation of membrane-associated DshdDAAM complexes in S2 cells. This result, together with our genetic data, suggests that DDAAM acts as the downstream effector of a Fz/Dsh module, which is required for the correct growth and guidance of the dorsal $\mathrm{MB}$ axon branches (Fig. 10).

In addition to their potential connection to Fz signaling in the dorsal lobe, we linked dDAAM and Dsh to Vang- and Wnt5-dependent ML development as well. Wnt5 and Vang have an identical effect on ML development when overexpressed, and this GOF phenotype can be suppressed by the same set of mutations ( $d D A A M, d s h, R a c 1)$. In particular, the putative PCP-null $d s h^{1}$ allele and heterozygosity for Rac1 cause an almost equally strong, yet partial, suppression with regard to the ML fusion phenotype. This is best explained by assuming that Wnt5 and Vang signal both in a Dsh-dependent and in a Dsh-independent, but Rac-dependent, manner. With regard to dDAAM, we have shown that $D D A A M$ nearly completely suppresses the GOF of Wnt5 and Vang, and we found that Dsh and Racl both contribute to dDAAM activation. Collectively, these data suggest a model in which Wnt5 and Vang promote $\beta$ lobe extension by signaling to Dsh and Rac1 that will activate dDAAM in parallel to each other (Fig. 10). The colocalization of Vang and dDAAM, observed in S2 cells, indicates that they may bind each other directly, which would be in good accordance with genetic data suggesting a close functional link between dDAAM and Vang during $\beta$ lobe development. However, formins are not known to bind Vang proteins; therefore, an indirect interaction, mediated by Rac1, which has recently been shown to be bound and redistributed by Vangl2 in epithelial cell lines (Lindqvist et al., 2010), appears a more likely possibility.

As discussed above, and contrary to Vang, $\mathrm{Fz}$ does not appear to be required for ML development, or if anything, it might play an opposite role, as loss of $f z$ leads to ML fusion in $16.1 \%$ of the lobes (Fig. $8 \mathrm{~J}, \mathrm{~K}$ ). This is a surprising observation at first glance as Wnt proteins are thought to activate members of the Fz receptor family, but former analysis of Wnt5 signaling during $\mathrm{MB}$ development also failed to reveal a Fz require- 
ment in the $\beta$ lobes (Grillenzoni et al., 2007). Instead, Wnt5 has been linked to other type of Wnt receptors, the Ryk/Derailed atypical tyrosine kinase receptors, which are known to be involved in axonal guidance in flies (Grillenzoni et al., 2007; Sakurai et al., 2009) and vertebrates (Liu et al., 2005; Keeble et al., 2006; Schmitt et al., 2006; Fradkin et al., 2010). In light of these results, it will be of future interest to analyze the Wnt5Vang connection in the MB in more details and identify the Wnt5 receptor in this context.

Consistent with the lack of lobe-specific requirement for $d s h$ and $D D A A M$, our studies revealed that Dsh, dDAAM, and Rac1 are used as common effector elements of a dorsal lobe-specific Fz-dependent signal and a Vang-dependent ML-specific signal. It follows that Dsh and DDAAM are likely to take part in two types of PCP complexes. Although, in vitro, Dsh has the ability to interact with both Fz and Vang (Rothbächer et al., 2000; Bastock et al., 2003; Wong et al., 2003; Jenny et al., 2005), the conclusion that Dsh functions downstream of Vang in the $\beta$ lobes is markedly different from the classical PCP regulatory context in which the Fz/Dsh and Vang/Pk complexes have opposing effects (Adler, 2002; Maung and Jenny, 2011). Thus, this result, together with the Wnt5-Vang data, substantiates the earlier findings that the PCP system operates at least partly differently in neurons than during tissue polarity signaling ( $\mathrm{Ng}, 2012)$.

During PCP signaling, the vertebrate DAAM orthologs control convergence and extension movements, polarized cell movements during vertebrate gastrulation (Habas et al., 2001; Wang and Nathans, 2007). In contrast, $d D A A M$ is dispensable for classical planar polarity establishment in flies (Matusek et al., 2006), suggesting that the tissue polarity function of DAAM might be restricted only to vertebrates. Despite the lack of direct function in establishing tissue polarization, we provide evidence that dDAAM is linked to the PCP pathway in another important regulatory context, notably directed neuronal development in the adult brain. Consistent with our results, recent studies revealed that PCP signaling and DAAM regulate neural development in planarians and in Xenopus embryos (Beane et al., 2012). Given that the vertebrate PCP proteins are known to be involved in multiple aspects of CNS development (Wada and Okamoto, 2009; Tissir and Goffinet, 2010), and the vertebrate DAAM orthologs are strongly expressed in the CNS (Nakaya et al., 2004; Kida et al., 2007), it is conceivable that the PCP/DAAM module represents a highly conserved regulatory system that is used to regulate various aspects of neuronal development throughout evolution.

\section{References}

Adler PN (2002) Planar signaling and morphogenesis in Drosophila. Dev Cell 2:525-535. CrossRef Medline

Ang SF, Zhao ZS, Lim L, Manser E (2010) DAAM1 is a formin required for centrosome re-orientation during cell migration. PLoS One 5:e13064. CrossRef Medline

Axelrod JD, Miller JR, Shulman JM, Moon RT, Perrimon N (1998) Differential recruitment of Dishevelled provides signaling specificity in the planar cell polarity and Wingless signaling pathways. Genes Dev 12:2610-2622. CrossRef Medline

Barkó S, Bugyi B, Carlier MF, Gombos R, Matusek T, Mihály J, Nyitrai M (2010) Characterization of the biochemical properties and biological function of the formin homology domains of Drosophila DAAM. J Biol Chem 285:13154-13169. CrossRef Medline

Bastock R, Strutt H, Strutt D (2003) Strabismus is asymmetrically localised and binds to Prickle and Dishevelled during Drosophila planar polarity patterning. Development 130:3007-3014. CrossRef Medline

Beane WS, Tseng AS, Morokuma J, Lemire JM, Levin M (2012) Inhibition of planar cell polarity extends neural growth during regeneration, homeostasis, and development. Stem Cells Dev 21:2085-2094. CrossRef Medline
Bolte S, Cordelières FP (2006) A guided tour into subcellular colocalization analysis in light microscopy. J Microsc 224:213-232. CrossRef Medline

Boutros M, Paricio N, Strutt DI, Mlodzik M (1998) Dishevelled activates JNK and discriminates between JNK pathways in planar polarity and wingless signaling. Cell 94:109-118. CrossRef Medline

Boutros M, Mihály J, Bouwmeester T, Mlodzik M (2000) Signaling specificity by Frizzled receptors in Drosophila. Science 288:1825-1828. CrossRef Medline

Chesarone MA, DuPage AG, Goode BL (2010) Unleashing formins to remodel the actin and microtubule cytoskeletons. Nat Rev Mol Cell Biol 11:62-74. CrossRef Medline

Chilton JK (2006) Molecular mechanisms of axon guidance. Dev Biol 292: 13-24. CrossRef Medline

Clemens JC, Worby CA, Simonson-Leff N, Muda M, Maehama T, Hemmings BA, Dixon JE (2000) Use of double-stranded RNA interference in Drosophila cell lines to dissect signal transduction pathways. Proc Natl Acad Sci U S A 97:6499-6503. CrossRef Medline

Fanto M, Weber U, Strutt DI, Mlodzik M (2000) Nuclear signaling by Rac and Rho GTPases is required in the establishment of epithelial planar polarity in the Drosophila eye. Curr Biol 10:979-988. CrossRef Medline

Fradkin LG, Dura JM, Noordermeer JN (2010) Ryks: new partners for Wnts in the developing and regenerating nervous system. Trends Neurosci 33: 84-92. CrossRef Medline

Gonçalves-Pimentel C, Gombos R, Mihály J, Sánchez-Soriano N, Prokop A (2011) Dissecting regulatory networks of filopodia formation in a Drosophila growth cone model. PLoS One 6:e18340. CrossRef Medline

Goodrich LV (2008) The plane facts of PCP in the CNS. Neuron 60:9-16. CrossRef Medline

Goodrich LV, Strutt D (2011) Principles of planar polarity in animal development. Development 138:1877-1892. CrossRef Medline

Grillenzoni N, Flandre A, Lasbleiz C, Dura JM (2007) Respective roles of the DRL receptor and its ligand WNT5 in Drosophila mushroom body development. Development 134:3089-3097. CrossRef Medline

Habas R, Kato Y, He X (2001) Wnt/Frizzled activation of Rho regulates vertebrate gastrulation and requires a novel Formin homology protein Daam1. Cell 107:843-854. CrossRef Medline

Habas R, Dawid IB, He X (2003) Coactivation of Rac and Rho by Wnt/ Frizzled signaling is required for vertebrate gastrulation. Genes Dev 17: 295-309. CrossRef Medline

Harris ES, Rouiller I, Hanein D, Higgs HN (2006) Mechanistic differences in actin bundling activity of two mammalian formins, FRL1 and mDia2. J Biol Chem 281:14383-14392. CrossRef Medline

Heisenberg M, Borst A, Wagner S, Byers D (1985) Drosophila mushroom body mutants are deficient in olfactory learning. J Neurogenet 2:1-30. CrossRef Medline

Huber AB, Kolodkin AL, Ginty DD, Cloutier JF (2003) Signaling at the growth cone: ligand-receptor complexes and the control of axon growth and guidance. Annu Rev Neurosci 26:509-563. CrossRef Medline

Jenny A, Reynolds-Kenneally J, Das G, Burnett M, Mlodzik M (2005) Diego and Prickle regulate Frizzled planar cell polarity signalling by competing for Dishevelled binding. Nat Cell Biol 7:691-697. CrossRef Medline

Keeble TR, Halford MM, Seaman C, Kee N, Macheda M, Anderson RB, Stacker SA, Cooper HM (2006) The Wnt receptor Ryk is required for Wnt5a-mediated axon guidance on the contralateral side of the corpus callosum. J Neurosci 26:5840-5848. CrossRef Medline

Kida YS, Sato T, Miyasaka KY, Suto A, Ogura T (2007) Daaml regulates the endocytosis of EphB during the convergent extension of the zebrafish notochord. Proc Natl Acad Sci U S A 104:6708-6713. CrossRef Medline

Lee RC, Clandinin TR, Lee CH, Chen PL, Meinertzhagen IA, Zipursky SL (2003) The protocadherin Flamingo is required for axon target selection in the Drosophila visual system. Nat Neurosci 6:557-563. CrossRef Medline

Lee T, Luo L (1999) Mosaic analysis with a repressible cell marker for studies of gene function in neuronal morphogenesis. Neuron 22:451-461. CrossRef Medline

Lee T, Lee A, Luo L (1999) Development of the Drosophila mushroom bodies: sequential generation of three distinct types of neurons from a neuroblast. Development 126:4065-4076. Medline

Lindqvist M, Horn Z, Bryja V, Schulte G, Papachristou P, Ajima R, Dyberg C, Arenas E, Yamaguchi TP, Lagercrantz H, Ringstedt T (2010) Vang-like protein 2 and Racl interact to regulate adherens junctions. J Cell Sci 123:472-483. CrossRef Medline 
Liu W, Sato A, Khadka D, Bharti R, Diaz H, Runnels LW, Habas R (2008) Mechanism of activation of the Formin protein Daam1. Proc Natl Acad Sci U S A 105:210-215. CrossRef Medline

Liu Y, Shi J, Lu CC, Wang ZB, Lyuksyutova AI, Song XJ, Zou Y (2005) Ryk-mediated Wnt repulsion regulates posterior-directed growth of corticospinal tract. Nat Neurosci 8:1151-1159. CrossRef Medline

Lowery LA, Van Vactor D (2009) The trip of the tip: understanding the growth cone machinery. Nat Rev Mol Cell Biol 10:332-343. CrossRef Medline

Lu J, Meng W, Poy F, Maiti S, Goode BL, Eck MJ (2007) Structure of the FH2 domain of Daam1: implications for formin regulation of actin assembly. J Mol Biol 369:1258-1269. CrossRef Medline

Matusek T, Djiane A, Jankovics F, Brunner D, Mlodzik M, Mihály J (2006) The Drosophila formin DAAM regulates the tracheal cuticle pattern through organizing the actin cytoskeleton. Development 133:957-966. CrossRef Medline

Matusek T, Gombos R, Szécsényi A, Sánchez-Soriano N, Czibula A, Pataki C, Gedai A, Prokop A, Raskó I, Mihály J (2008) Formin proteins of the DAAM subfamily play a role during axon growth. J Neurosci 28:1331013319. CrossRef Medline

Maung SM, Jenny A (2011) Planar cell polarity in Drosophila. Organogenesis 7:165-179. CrossRef Medline

Mihály J, Matusek T, Pataki C (2005) Diego and friends play again. FEBS J 272:3241-3252. CrossRef Medline

Molnár I, Migh E, Szikora S, Kalmár T, Végh AG, Deák F, Barkó S, Bugyi B, Orfanos Z, Kovács J, Juhász G, Váró G, Nyitrai M, Sparrow J, Mihály J (2014) DAAM is required for thin filament formation and Sarcomerogenesis during muscle development in Drosophila. PLoS Genet 10: e1004166. CrossRef Medline

Nakaya MA, Habas R, Biris K, Dunty WC Jr, Kato Y, He X, Yamaguchi TP (2004) Identification and comparative expression analyses of Daam genes in mouse and Xenopus. Gene Expr Patterns 5:97-105. CrossRef Medline

Ng J (2012) Wnt/PCP proteins regulate stereotyped axon branch extension in Drosophila. Development 139:165-177. CrossRef Medline

Petrova IM, Lahaye LL, Martiáñez T, de Jong AW, Malessy MJ, Verhaagen J, Noordermeer JN, Fradkin LG (2013) Homodimerization of the Wnt receptor DERAILED recruits the Src family kinase SRC64B. Mol Cell Biol 33:4116-4127. CrossRef Medline

Prokop A, Sánchez-Soriano N, Gonçalves-Pimentel C, Molnár I, Kalmár T, Mihály J (2011) DAAM family members leading a novel path into formin research. Commun Integr Biol 4:538-542. CrossRef Medline

Rothbächer U, Laurent MN, Deardorff MA, Klein PS, Cho KW, Fraser SE
(2000) Dishevelled phosphorylation, subcellular localization and multimerization regulate its role in early embryogenesis. EMBO J 19:1010 1022. CrossRef Medline

Sakurai M, Aoki T, Yoshikawa S, Santschi LA, Saito H, Endo K, Ishikawa K, Kimura K, Ito K, Thomas JB, Hama C (2009) Differentially expressed Drl and Drl-2 play opposing roles in Wnt5 signaling during Drosophila olfactory system development. J Neurosci 29:4972-4980. CrossRef Medline

Schmitt AM, Shi J, Wolf AM, Lu CC, King LA, Zou Y (2006) Wnt-Ryk signalling mediates medial-lateral retinotectal topographic mapping. Nature 439:31-37. CrossRef Medline

Senti KA, Usui T, Boucke K, Greber U, Uemura T, Dickson BJ (2003) Flamingo regulates $\mathrm{R} 8$ axon-axon and axon-target interactions in the Drosophila visual system. Curr Biol 13:828-832. CrossRef Medline

Shimizu K, Sato M, Tabata T (2011) The Wnt5/planar cell polarity pathway regulates axonal development of the Drosophila mushroom body neuron. J Neurosci 31:4944-4954. CrossRef Medline

Tanaka NK, Tanimoto H, Ito K (2008) Neuronal assemblies of the Drosophila mushroom body. J Comp Neurol 508:711-755. CrossRef Medline

Tissir F, Goffinet AM (2010) Planar cell polarity signaling in neural development. Curr Opin Neurobiol 20:572-577. CrossRef Medline

Verkhusha VV, Otsuna H, Awasaki T, Oda H, Tsukita S, Ito K (2001) An enhanced mutant of red fluorescent protein DsRed for double labeling and developmental timer of neural fiber bundle formation. J Biol Chem 276:29621-29624. CrossRef Medline

Wada H, Okamoto H (2009) Roles of planar cell polarity pathway genes for neural migration and differentiation. Dev Growth Differ 51:233-240. CrossRef Medline

Wallar BJ, Alberts AS (2003) The formins: active scaffolds that remodel the cytoskeleton. Trends Cell Biol 13:435-446. CrossRef Medline

Wang Y, Nathans J (2007) Tissue/planar cell polarity in vertebrates: new insights and new questions. Development 134:647-658. CrossRef Medline

Wong HC, Bourdelas A, Krauss A, Lee HJ, Shao Y, Wu D, Mlodzik M, Shi DL, Zheng J (2003) Direct binding of the PDZ domain of Dishevelled to a conserved internal sequence in the $\mathrm{C}$-terminal region of Frizzled. Mol Cell 12:1251-1260. CrossRef Medline

Xu Y, Moseley JB, Sagot I, Poy F, Pellman D, Goode BL, Eck MJ (2004) Crystal structures of a Formin Homology-2 domain reveal a tethered dimer architecture. Cell 116:711-723. CrossRef Medline

Yam PT, Charron F (2013) Signaling mechanisms of non-conventional axon guidance cues: the Shh, BMP and Wnt morphogens. Curr Opin Neurobiol 23:965-973. CrossRef Medline 